\title{
Thermodynamics and solvent linkage of
}

\section{macromolecule-ligand interactions}

\author{
Michael R. Duff, Jr. and Elizabeth E. Howell* \\ Department of Biochemistry, Cellular, and Molecular Biology \\ University of Tennessee, Knoxville, TN 37996-0840
}

*Corresponding Author: Elizabeth E. Howell, Department of Biochemistry, Cell and

Molecular Biology, University of TN, Knoxville, TN 37996-0840; phone, 1-865-974-

4507; fax, 1-865-974-6306; e-mail, 1zh@utk.edu.

$\dagger$ This work was supported by NIH grant 1R15GM110669. 


\subsection{Introduction}

A grand challenge in binding is the prediction of ligand affinity. This ability is desired in drug design, but is still lacking. One critical factor that is often overlooked is the role of solvent and/or solute in binding. In vitro assays typically involve high concentrations of water while in vivo assays involve high concentrations of macromolecules and metabolites that exist in the cell. How accurate/relevant is the binding measured in dilute conditions compared to the crowded cell? How do hydration and desolvation affect binding? Can solvation effects be deconvoluted from the observed enthalpy? Does the presence of other solutes affect affinity? Do osmolytes have different effects than crowders? This review considers some of the calorimetry studies that address these questions.

Ligand binding can be described by the following equation:

$$
\mathrm{M}+\mathrm{L} \leftrightarrows \mathrm{ML}
$$

where $\mathrm{M}$ is the macromolecule and $\mathrm{L}$ is the ligand. Binding is described by the association constant, $\mathrm{K}_{\mathrm{a}}$, and the Gibbs free energy, $\Delta \mathrm{G}$, which equals -RT $\ln \mathrm{K}_{\mathrm{a}}$. Another common equation is $\Delta \mathrm{G}=\Delta \mathrm{H}-\mathrm{T} \Delta \mathrm{S}$ where $\Delta \mathrm{H}$ is the enthalpy (a measure of the energy of interaction between the binding partners), $T$ is the temperature and $\Delta S$ is the entropy (a measure of the order of the system). Isothermal titration calorimetry (ITC) allows direct measurement of the enthalpy as well as the stoichiometry and $\mathrm{K}_{\mathrm{a}}$ associated with binding. Since molecules are hydrated in solution, the observed $\Delta \mathrm{H}$ is composed of two parts, the intrinsic enthalpy associated with binding and the effect due to solvation. This relationship is described in equation 2 below as well as the Born-Haber cycle (Figure 1).

$$
\Delta \mathrm{H}_{\text {observed }}=\Delta \mathrm{H}_{\text {intrinsic }}+\Delta \mathrm{H}_{\text {solvation }}
$$

From the Born-Haber cycle, desolvation plays a role in binding. Water can also play an important role in binding and specificity by filling structural voids and also serving as a bridge between surfaces.

\subsection{Solvent Effects Near Hydrophobic Surfaces}

In a classical description of the hydrophobic effect, solvation of a hydrophobic surface involves ordering of water. Clathrate or iceberg structures have been observed for water near a hydrophobic surface. This behavior predicts that association of two hydrophobic surfaces will be entropy driven as the released water molecules will be more disordered as they enter the bulk solvent. Examples of entropy driven binding include early inhibitors of the AIDs protease [1] and a variant of subtilisin BPN' binding to GroEL [2]. Both systems show endothermic peaks in ITC titrations. Many other examples exist. 
More recently however, Chandler has suggested water near an extended hydrophobic surface has properties similar to gas phase water [3, 4]. In this case, water acts as if it is at a liquid-vapor interface and the water density has a larger variation as compared to bulk water. This model allows biomolecules to lose waters more readily (dewetting) to assemble via hydrophobic interactions. Melittin and 2,3dihydroxybiphenyl dioxygenase were predicted to be near a dewetting-wetting transition and mutations were proposed to shift the equilibria towards one side of the transition or the other [4]. One could predict that using different solutes would also alter the ability of these assemblies to form.

\subsection{Enthalpy Driven Hydrophobic Effects?}

To study the role of water on hydrophobic effects, ITC is typically coupled with additional structural information derived from crystallography or nuclear magnetic resonance (NMR) experiments. For example, the Klebe lab has studied water effects in thermolysin using ITC and high resolution crystal structures [5-7]. Using ligands with either a terminal methyl or a terminal carboxylate or both moieties that bind in the S2' site, they find that the energetics are dependent on the route taken to the doubly substituted ligand [5]. In other words, $\mathrm{a}-\mathrm{CH}_{3}$ group has a different effect when added to the initial molecule or when added to the derivative possessing the carboxylate group. As the ligands show almost identical binding modes, their non-predictable behavior was proposed to be associated with differences in the first hydration shell surrounding the ligands. The Klebe lab found that the larger and more cohesive the water network formed on the surface of the bound ligand, the greater the enthalpy associated with binding. In this "non-classical hydrophobic effect," a more negative enthalpy was observed when rigid water networks formed on the surface of a hydrophobic ligand in the bound complex. In other studies by this group [6,7], a series of 12 different ligands was examined where the substituent binding to the S2' site in thermolysin ranged from hydrogen to longer alkyl chains to a benzene moiety. While the $\Delta \mathrm{G}$ varied from -7.52 to $-9.73 \mathrm{kcal} / \mathrm{mol}(\Delta \Delta \mathrm{G}=2.21 \mathrm{kcal} / \mathrm{mol})$, the associated enthalpy varied from -2.50 to -8.03 $\mathrm{kcal} / \mathrm{mol}(\Delta \Delta \mathrm{H}=5.53 \mathrm{kcal} / \mathrm{mol})$, a much larger range. All these data sets led the authors to conclude that desolvation is not the sole driving force in binding as addition of more methyl groups does not linearly affect the $\Delta \mathrm{G}$ and $\Delta \mathrm{H}$ values. Rather the authors posit that water which bridges from the bound ligand surface to bulk water strongly impacts the thermodynamics of the interaction. If a strong network of $\mathrm{H}$-bonds is formed in the first hydration shell of the complex, this contributes to an enthalpic signature associated with binding.

Another window on the hydrophobic effect is provided by studies of human carbonic anhydrase II (HCA) by the Whitesides group [8-10]. Most recently, they have monitored the thermodynamics of binding by benzothiazole sulfonamide that has been substituted with one to four fluorines [8]. While substitution of fluoride for hydrogen does not greatly alter the ligand size, fluorination does alter the dipole moment of the ligand, which can in turn affect the active site water network. Binding of eight fluorinated ligands to HCA was examined by ITC and no substantial change in the $\Delta \mathrm{G}$ associated with binding was found. However the $\Delta \mathrm{H}$ values for two members of the 
series were found to vary by up to $5 \mathrm{kcal} / \mathrm{mol}$. Crystallography studies found no changes in structure for either the protein or these two bound ligands. Computational WaterMap predictions of the associated entropy suggest a linkage of the entropy changes with ligand desolvation. They conclude desolvation and positioning of the active site water network both contribute to the observed enthalpy change.

An alternate solution to how proteins may affect solvent and thus the entropy associated with binding has been uncovered by the Homans group [11-15]. They study pheromone binding in mouse major urinary protein (MUP), a lipocalin. The pheromones are hydrophobic yet binding is enthalpy driven. This group has deconvoluted the various enthalpy and entropy terms associated with the Born-Haber cycle (see Table 2 in Homans reference [11]). As the pheromone is volatile, they can measure its partitioning between water and the gas phase to describe ligand desolvation [12]. To measure changes in the degrees of freedom associated for the protein in the bound vs. the unbound state, they use NMR. Surprisingly, while residues in the active site of MUP tighten upon ligand binding, the rest of the molecule becomes more dynamic [14]. Further, the active site is not well solvated. The active site of MUP is occluded and the sock shape of the binding pocket precludes contact of any bound water in the apo enzyme with bulk water [16]. Since there is little water to remove from the active site, the desolvation penalty is minimal. (Other groups have found dry active sites, supporting this condition [16, 17].) Changes in the degrees of freedom for the ligand upon binding were calculated $[14,18]$. The Homans group concluded that the dry active site does not contribute to the observed entropy, allowing the enthalpic signal to predominate.

One signature of changes in water structure appears to be enthalpy-entropy compensation. Results from both the Klebe and Whitesides groups support this notion, previously proposed by Ben-Naim [19], Karplus [20] and Fersht [21].

To summarize, formation of water networks near hydrophobic surfaces can contribute to the observed enthalpy. In addition, dewetting of protein active sites can provide an alternate route to allowing enthalpy driven hydrophobic binding.

\subsection{Heat Capacity Changes}

Heat capacity describes the ability of a substance to absorb heat without a change in temperature. Previously a change in heat capacity $\left(\Delta \mathrm{C}_{\mathrm{p}}\right)$ has been correlated with changes in the accessible surface area involved in binding [22-24]. The $\Delta \mathrm{C}_{\mathrm{p}}$ typically ascribed to a hydrophobic effect is negative. This contains a solvent reorganization component as when the ordered waters from the hydrophobic surface move to bulk solution, they are able to absorb more energy. Conversely, waters that are less ordered on a hydrophilic surface have a higher energy and do not release as much energy when they move to bulk solvent. Therefore the $\Delta \mathrm{C}_{\mathrm{p}}$ for a hydrophilic binding event is expected to be positive.

Cooper, in his excellent review of heat capacity effects, describes a further role for water [25]. Of particular interest is the prediction that trapping of water molecules 
will provide enthalpic contributions. In general, he proposes "significant $\Delta \mathrm{C}_{\mathrm{p}}$ effects are to be expected for any macromolecular process involving a multiplicity of cooperative weak interactions of whatever kind" [25]. Experimental examples include trapping of water due to introduction of a mutation in DNA gyrase [26], uptake of water associated with dimerization of the $\beta$-lactoglobulin dimer [27], binding of different ligands by cyclophilin [28], binding of DNA by a TATA-box binding protein [29] and others [30]. In general, experimental estimates of the effect on $\Delta \mathrm{C}_{\mathrm{p}}$ per trapped water molecule range from $-18 \mathrm{cal} \mathrm{mol}^{-1} \mathrm{~K}^{-1}$ to $-60 \pm 8 \mathrm{cal} \mathrm{mol}^{-1} \mathrm{~K}^{-1}[25,31]$.

\subsection{Thermodynamic Solvent Isotope Effects}

The Toone lab pioneered the use of $\mathrm{D}_{2} \mathrm{O}$ to analyze the role of solvent in ligand binding $[32,33]$. This approach arose as the properties of $\mathrm{D}_{2} \mathrm{O}$ differ from normal water; for example, there is roughly a $10 \%$ change in the enthalpy for a hydrogen bond in $\mathrm{D}_{2} \mathrm{O}$ versus $\mathrm{H}_{2} \mathrm{O}$ [34-36]. This energy difference helps estimate the contribution of solvent reorganization during binding. Specifically, the binding enthalpy is monitored in water and then in $\mathrm{D}_{2} \mathrm{O}$. The $\Delta \Delta \mathrm{H}\left(=\Delta \mathrm{H}_{\mathrm{H} 2 \mathrm{O}^{-}} \Delta \mathrm{H}_{\mathrm{D} 2 \mathrm{O}}\right)$ is then multiplied by a factor of 10 to estimate the role of solvent reorganization in binding. (As the signal change is only $10 \%$, yet this accounts for a complete $H$ to D substitution(s), to return to the worth or enthalpic contribution of the hydrogen bond(s), the $\Delta \Delta \mathrm{H}$ difference is multiplied by 10$)$. A potential complication in the solvent isotope effect is exchange of the protons involved in formation of hydrogen bonds between the ligand and macromolecule. This could alter the observed binding enthalpy. However if the structures of the ligand, protein, and complex are identical in both solvents and if both the functional groups in the ligand and macromolecule that form the hydrogen bond(s) also form hydrogen bonds with solvent in the unbound state, then the difference in enthalpy from the loss of $\mathrm{D}_{2} \mathrm{O} \cdot$ donor/acceptor interactions versus the $\mathrm{H}_{2} \mathrm{O} \cdot$ donor/acceptor interactions will counteract the difference in enthalpy from ligand·macromolecule hydrogen bonds containing deuteriums as compared to protons. Using this approach, Chervenak and Toone monitored binding of sugars to lectins and found solvent reorganization contributed from 25 to $100 \%$ to the overall observed enthalpy [32]. They also found a reasonably linear relationship between $\Delta \mathrm{C}_{\mathrm{p}}$ and $\Delta \Delta \mathrm{H}$ for 6 samples including $\mathrm{CMP}$ binding to RNase, suggesting a predominant contribution to heat capacity can arise from solvent re-organization.

Additional studies comparing the enthalpy of binding in $\mathrm{H}_{2} \mathrm{O}$ vs $\mathrm{D}_{2} \mathrm{O}$ have mostly focused on carbohydrates and found large contributions from solvent re-organization [37, 38]. In studies of kanamycin binding to aminoglycoside phosphotransferase (3')-IIIa (APH), the Serpersu lab found the enthalpy to be less negative in $\mathrm{D}_{2} \mathrm{O}$ compared to $\mathrm{H}_{2} \mathrm{O}$ $[39,40]$; this is the trend seen with other carbohydrates. Surprisingly, binding of neomycins to APH yielded more negative $\Delta \mathrm{H}$ values in $\mathrm{D}_{2} \mathrm{O}$. In conjunction with NMR studies showing apo APH behaves like a molten globule, the Serpersu lab suggests that binding of kanamycin alters the solvent structure differently than binding of neomycin. A break in slope in the heat capacity plot $\left(\right.$ at $30^{\circ} \mathrm{C}$ ) describing kanamycin binding was suggested to correspond with solvent reorganization effects dominating at temperatures $>$ $30^{\circ} \mathrm{C}$ and with vibrational modes contributing more strongly at lower temperatures [39, 40]. 
For binding of dihydrofolate (DHF) to the binary complex of R67 dihydrofolate reductase-NADP ${ }^{+}$, our lab finds the same $\mathrm{K}_{\mathrm{d}}\left(=1 / \mathrm{K}_{\mathrm{a}}\right)$ in $\mathrm{H}_{2} \mathrm{O}$ and $\mathrm{D}_{2} \mathrm{O}$ (e.g. $2.59 \mu \mathrm{M}$ ). However the enthalpy is different with values of $-10.4 \pm 0.04 \mathrm{kcal} / \mathrm{mol}$ and $-9.21 \pm 0.04$ $\mathrm{kcal} / \mathrm{mol}$ in protiated and deuterated solvent respectively [41]. The $\Delta \Delta \mathrm{H}$ value is -1.18 $\mathrm{kcal} / \mathrm{mol}$. Using Chervenak and Toone's factor of 10 to assess the contribution of solvent reorganization to the observed enthalpy yields an enthalpic signal of $-11.8 \mathrm{kcal} / \mathrm{mol}$. While this difference is slightly higher than $\Delta \mathrm{H}$ observed in water, it suggests that water reorganization dominates the enthalpic signal associated with DHF binding.

A more recent study of $\mathrm{D}_{2} \mathrm{O}$ effects in the biotin repressor found water reorganization was important in protein dimerization [42]. In studying binding of DNA to the cAMP repressor protein ${ }^{\circ}$ AMP complex, Shi et al. found a more positive enthalpy in $\mathrm{D}_{2} \mathrm{O}$ than $\mathrm{H}_{2} \mathrm{O}$ [43]. Also Connelly found a lower enthalpy contribution for binding of tacrolimus and rapamycin to FK506 binding protein in $\mathrm{D}_{2} \mathrm{O}$ [44]. These various examples indicate the likely widespread nature of solvent reorganization on ligand binding.

\subsection{Osmotic Stress Experiments Probe the Role of Water}

Osmolytes are small molecules that take up volume in a solution, altering the concentration, and thus the activity, of water. Decreasing the concentration of the bulk water alters the hydration of the ligand and biomacromolecule. Osmolytes can be preferentially excluded from the surfaces of ligands or biomacromolecules. For example, glycine betaine, also known as trimethylglycine, cannot serve as a $\mathrm{H}$-bond donor, thus proteins prefer to interact with water rather than betaine. Betaine has been proposed to be the most excluded osmolyte from protein surfaces [45]. Alternatively, the relevant surfaces may prefer to interact with the osmolytes as opposed to water; this is the preferential interaction model (Figure 2). Measuring the affinity of a ligand for a biomacromolecule in buffer, as well as in buffer containing osmolytes, will yield the change in the number of waters upon ligand binding (Equation 3) [46-49] :

$$
\frac{\partial \ln \left(K_{a}\right)}{\partial \ln (o s m)}=-\frac{\Delta n_{w}}{55.6}
$$

where $\mathrm{K}_{\mathrm{a}}$ is the binding association constant obtained from a method such as ITC, osm is the osmolality of the buffer used, 55.6 is the molarity of water and $\Delta \mathrm{n}_{\mathrm{w}}$ is the change in the number of hydrating waters upon complex formation.

\subsection{The Typical Osmotic Stress Result is Water Release Upon Ligand Binding}

Addition of osmolyte typically tightens binding as a lower water concentration leads to easier desolvation of the surfaces coming together. To ensure that water is the variable rather than changes in solvent dielectric or viscosity, several different osmolytes are typically used. If they all have the same effect, then changes in water activity are the driving force affecting the binding equilibrium. To estimate the number of waters 
released upon binding, $\Delta \mathrm{n}_{\mathrm{w}}$, the difference in accessible surface area is typically calculated from the crystal structure of the complex minus that of the apo protein and free ligand divided by the typical area of a water molecule $[50,51]$.

As a first example of tighter association, the binding of guanosine monophosphate (GMP) to guanylate kinase (GK) was monitored in the presence of polyethylene glycols (PEGs) with a range of sizes [48]. The GMP-GK binding affinity increased as PEGs were added. It was found that as the size of the PEG increased, there was a larger change in the number of hydrating waters. Binding of GMP to GK releases 58 waters based on ITC results in the presence of PEG400. Release of 100 waters was also noted for adenosine diphosphate (ADP) binding to apo-GK as well as the GMP-GK binary complex in the presence of $\mathrm{Mg}^{2+}$. Small angle neutron scattering (SANS) yielded similar changes in waters for the formation of the ADP-GMP-GK ternary complex $\left(\Delta \mathrm{n}_{\mathrm{w}} \approx 120\right)$ and the GMP-GK binary complex $\left(\Delta \mathrm{n}_{\mathrm{w}} \approx 30\right)$. ITC studies were used to show that the SANS results were due to changes in hydration of the GK protein, and that there were not additional effects on the protein structure, such as closing of the ligand binding site cleft. Since both ITC and SANS experiments yielded similar changes in waters, it could be concluded that there were no changes in protein structure in the presence of osmolytes.

Osmolytes can also be used to explore the binding of proteins to DNA. The binding of a 20-mer DNA duplex containing its target sequence to the TATA-box binding protein (TBP) from the hyperthermophilic archaeon Pyrococcus woesei was studied [52]. ITC titrations were performed in betaine, sucrose, glycerol and triethylene glycol (TEG). No change in the binding affinity was noted in the presence of glycerol or TEG. In the case of betaine and sucrose, the $\mathrm{K}_{\mathrm{d}}$ decreases 18 and 5-fold, respectively. From the effect of osmolytes on affinity, $24 \pm 2$ and $16 \pm 1$ waters were calculated to be released for betaine and sucrose, respectively, on TBP binding to its target sequence. In an independent experiment which monitored the effect of salt on binding, similar values for water release were obtained when the data were fit to equation 1 in Bergqvist et al. that included terms for both salt and water effects [52].

Another example is tighter binding of the cofactor NADPH to three different dihydrofolate reductases [53-55]. The three different proteins are not homologous in sequence or structure (see Figure 3 for the structures). The first enzyme is a type I DHFR encoded by the chromosome of $E$. coli (EcDHFR). This enzyme is a target of the antibacterial drug, trimethoprim. A protein that provides resistance to trimethoprim is R67 DHFR, a type II DHFR. The third enzyme, FolM, is a pteridine reductase which catalyzes the DHFR reaction, albeit slowly. Figure 4A compares the cofactor ITC data for all three enzymes with betaine as the osmolyte. The slopes are similar, consistent with exclusion of betaine from the surface of the 3 different DHFRs. However when other osmolytes are tested, variable results are observed, suggesting FolM interacts with osmolytes while EcDHFR interacts to a lesser degree (see section 6.4).

\subsection{An Unusual Osmotic Stress Result is Weaker Binding}


While desolvation typically aids binding in the presence of osmolytes, there are numerous cases where weaker binding results. This behavior may arise due to additional water molecules mediating the interaction surfaces or from a conformational change coupled to binding such that the net effect is water uptake [56-59]. Another avenue for weaker binding is osmolyte interaction with one or both of the interacting partners (see section 6.4).

A first example of weaker binding in the presence of osmolytes describes lysozyme binding to the Fab fragment of a monoclonal antibody. Analysis of the crystal structure indicates that waters are involved in forming the contacts between the antibody and its epitope [60]. Binding of bobwhite quail egg white lysozyme to a murine antibody targeted against hen egg white lysozyme was measured by ITC in the presence of several osmolytes [61]. Bobwhite quail lysozyme contains an Arg $\rightarrow$ Lys mutation in the epitope region that makes binding to the antibody 1000 -fold weaker. Binding of bobwhite quail lysozyme to the antibody was weakened in the presence of osmolytes. The binding affinity decreased 6.5, 10 and 26-fold in the presence of 50\% glycerol, ethylene glycol and betaine, respectively. All three osmolytes yielded similar decreases in affinity with osmolality and were all fit to the same slope in Equation 3, yielding an uptake of $8 \pm 1$ waters.

In another example, Swaminathan et al. analyzed saccharide binding to Concanavalin A (ConA) by ITC under osmotic stress conditions (ethylene glycol and glycerol) to parse out the role of water in saccharide recognition by the lectin [62]. A decrease in binding affinity, with 5, 3 and 1 water molecules sequestered, was found for the mono, di and trisaccharides, respectively. These results indicate that waters are required for saccharide binding. Circular dichroism (CD) data indicated no structural change in ConA in the presence of osmolytes. Additionally, differential scanning calorimetry (DSC) data found that ConA is stabilized by addition of osmolytes suggesting that the decrease in binding is not due to destabilization of the lectin.

\subsection{The curious case of osmolytes interacting with ligands}

Another case of weakened binding in the presence of osmolytes is when there are interactions between the osmolytes and one of the binding partners. This is an example of the preferential interaction model (Figure 2B). Each osmolyte can interact differently with one or both of the binding partners, resulting in different slopes in plots of $\ln \left(\mathrm{K}_{\mathrm{a}}\right) \mathrm{vs}$. osmolality. While most examples describe osmolyte interaction with the protein, osmolytes can also interact with the ligand. In either case, they need to be removed to form the complex. If the osmolytes interact more strongly than water does, then the energy penalty for removing the osmolytes will decrease binding by lowering the affinity, which shifts the binding equilibrium towards the unbound state.

Osmolyte-ligand interactions have been noted when the role of water in the binding of dihydrofolate (DHF) to several types of dihydrofolate reductase (DHFR) enzymes was studied by our lab [53-55]. Binding studies were first performed using R67 DHFR, a type-II DHFR. This enzyme is a homotetramer with 2,2,2-symmetry. R67 
possesses a single active site pore where dihydrofolate (DHF) and NADPH bind to symmetry-related sites [63]. DHF binding to R67 DHFR became weaker in the presence of several osmolytes as shown in Figure 4B, C [53]. The decrease in binding could be due to the osmolytes interacting with either the protein or the free DHF ligand. However the increase in affinity for NADPH (see section 6.2), which has a binding site that is symmetry-related to the DHF binding site on R67 DHFR, indicates that decreased DHF affinity is not due to osmolytes interacting with the protein. A model of the effect of osmolyte-DHF associations on binding to DHFR is given in Figure 5.

A test of the osmolyte-DHF interaction model used $E$. coli chromosomal DHFR (EcDHFR), which is structurally unrelated to R67 DHFR. A similar set of results was observed. Binding of DHF to EcDHFR, as measured by ITC, was weaker in the presence of osmolytes compared to buffer alone, while NADPH binding was strengthened by addition of osmolytes [54]. Stopped-flow studies provided further insight into how osmolytes affected ligand binding. The presence of betaine mostly affects DHF binding via a decrease in $\mathrm{k}_{\text {on }}$, while betaine mostly affects NADPH binding via a decrease in $\mathrm{k}_{\text {off. }}$ The former was interpreted as betaine associating with the free DHF, which had to be removed prior to DHF binding to EcDHFR while the latter was attributed to water uptake upon complex dissociation [64].

Studies on a third protein with low DHFR activity utilized FolM [55]; this enzyme is a pteridine reductase and it shows similar trends to the other DHFRs. Steady state kinetics showed $20 \%$ betaine increased the $\mathrm{K}_{\mathrm{m}}$ for DHF 3.5 fold with no effect on $\mathrm{k}_{\text {cat }}$. ITC studies were additionally performed using the antifolate drug methotrexate as a model for DHF due to poor signal and instability of the latter. Methotrexate (MTX) affinity for FolM decreased in the presence of several osmolytes [55]. For NADPH, an increase in affinity was observed only when betaine and glycerol were used as osmolytes. NADPH bound more weakly to FolM in the presence of ethylene glycol, dimethylsulfoxide (DMSO) and PEG400. The secondary structure of FolM was unaffected by $20 \%$ glycerol, ethylene glycol or PEG400 according to CD. However, differential scanning calorimetry (DSC) experiments indicated that FolM was stabilized by either $20 \%$ betaine or glycerol, but was destabilized by $20 \%$ DMSO or ethylene glycol. The DSC results suggested an additional complicating layer where preferential interaction between FolM and some osmolytes occurred and affected the ITC results. While the decreased MTX affinity is indicative of osmolytes interacting with the folate analog, some of the decreased affinity is likely due to destabilization of FolM by the osmolytes. These results indicate that osmolyte-protein interactions can also complicate the analysis of ligand binding. If there are variable slopes in plots of $\ln K_{a}$ vs. osmolality, the effect of osmolytes on protein structure and stability can be examined by DSC to examine the possibility of osmolyte-protein interaction(s) [65-71].

The interaction of osmolytes with free DHF can be explained by preferential interaction, or solvation, of DHF by the osmolyte compared to water. The interactions between osmolytes and DHF are very weak, but slightly stronger than the hydration interactions between water and DHF. The relative hydrophobicity of folate, with a calculated water-octanol partition coefficient $(\log \mathrm{P})$ value of -3.875 , is one potential 
reason folate preferentially interacts with osmolytes compared to water. In addition, the Record group has developed an osmometry approach to calculate the preferential interaction (expressed as $\mu_{23} / \mathrm{RT}$ ) of a molecule with betaine, urea or proline [72-74]. In this approach, the osmolality of a solution with increasing betaine concentration (for example) is measured. Then the osmolality of the betaine solution plus a small compound such as benzoate is measured. If betaine interacts with sodium benzoate, the bulk concentration of water increases compared to the betaine only solution; this is measured by a vapor pressure osmometer. If betaine is excluded from benzoate, the bulk concentration of water decreases. The difference in slopes between the betaine only and the betaine plus benzoate solution allows calculation of $\mu_{23} / \mathrm{RT}$ values. By using many different small molecules, the $\mu_{23} / \mathrm{RT}$ values can be broken down into atomistic values, which allows prediction of the effects of betaine, proline and urea reasonably well. The focus of the Record lab is on protein folding while the focus of our lab is on ligand binding. Using Table 2 of Capp et al. [72], we calculated preferential interaction coefficients for betaine with folate, DHF and NADPH of $-0.04,0.13,1.11 \mathrm{~m}^{-1}$, respectively. Stronger association of a molecule with betaine compared to water is indicated by a negative $\mu_{23} / \mathrm{RT}$ value, while an increasingly positive $\mu_{23} / \mathrm{RT}$ is observed for ligands that preferentially interact with water compared to betaine. A molecule that prefers to interact with betaine is sodium benzoate, which has a low (negative) $\mu_{23} / \mathrm{RT}$ value, $-0.091 \mathrm{~m}^{-1}$. In contrast, potassium citrate does not interact with betaine $\left(\mu_{23} / \mathrm{RT}=\right.$ $1.2 \mathrm{~m}^{-1}$ ). To compare these calculated values with experimental values (such as DHF binding to DHFR), a preferential interaction value $\left(\Delta \mu_{23} / \mathrm{RT}\right)$ can be determined according to Capp et al. [72]:

$$
\frac{\Delta \mu_{23}}{R T}=\frac{\partial \ln \left(K_{a}\right)}{\partial m}
$$

The values for the predicted and experimentally determined preferential interaction coefficients differ for DHF and NADPH binding to DHFRs although the prediction does capture whether betaine will preferentially interact with the ligand or be excluded (Table 1). The discrepancies in the calculated and experimental values indicate there are still some deficiencies in the calculation method. The calculated values tend to overestimate preferential exclusion of a molecule. One reason may be that experimental values are obtained from binding data, while the theoretical values are calculated for the ligand only. Additionally, discrepancies may arise as the moieties on the ligand that preferentially exclude betaine might not participate as much in the binding event. Few, if any, waters/osmolytes would have to be removed from the non-participating moieties upon binding; this scenario would not affect the observed binding affinity to the same degree as the parts of the ligand that do participate in binding.

At this point, we note there are various approaches to analyze data from experiments where osmolytes are used to probe the role of water. Osmotic stress experiments use the effect of osmolality on binding to determine the release, or uptake, of waters upon ligand binding [46-48]. Alternately, the Record group calculates preferential interaction coefficients to describe the interaction between osmolytes and solutes [72-74]. Parsegian et al. argue that these approaches are two sides of the same coin [75]. For example, osmotic stress analysis of the data in Figure 4A using Eq. 3 indicates release of 
38 waters upon binding of NADPH to R67 DHFR. Using the same data, an experimental $\Delta \mu_{23} / \mathrm{RT}$ value of $0.43 \mathrm{~m}^{-1}$ can be calculated from Eq. 4 . Both methods consider preferential interaction, or exclusion of osmolyte, from the ligand and/or protein to understand the role of water in ligand binding. Osmotic stress focuses more on the changes in hydration, while the preferential interaction method examines the interactions, either positive or negative (i.e. association or exclusion), of the co-solute with the ligand or protein.

Using the above considerations, we propose for any ligand-protein system that binding should be weaker for molecules with negative $\mu_{23} / \mathrm{RT}$ values due to the extra energy required to remove these osmolytes from the ligand surface. We have further used the atomistic approach to predict betaine and proline interactions via a Python script to calculate $\mu_{23} / \mathrm{RT}$ values for a variety of ligands using the values in Table 2 of Capp et al. [72]. Since molecules with aromatic ring systems and/or guanidyl groups are predicted to interact strongly with betaine, we identified a water-soluble aromatic molecule as a test case to explore our ability to predict weaker binding due to osmolyteligand interactions. The binding of warfarin, a blood-thinning drug, to fatty acid-free bovine serum albumin (BSA) was used as a model system. The binding of warfarin to BSA and human serum albumin has been well studied for many decades [76-78]. Based on the structure of warfarin bound to human serum albumin (PDB ID 1H9Z) [79], warfarin is predicted to interact with both betaine and L-proline with $\mu_{23}$ /RT values of -0.52 and -0.15 , respectively. Additionally, using the vapor pressure osmometry approach, we experimentally found that the polyol, sorbitol, is preferentially excluded from benzoate with a $\mu_{23} / \mathrm{RT}$ of $0.18 \pm 0.02 \mathrm{~m}^{-1}$ (Figure 6). If sorbitol is preferentially excluded from the aromatic benzoate, this leads to the prediction that sorbitol will not associate with free warfarin in solution. This scenario then predicts that warfarin will bind more tightly to BSA due to desolvation effects.

To test our predictions using this model system, ITC was performed by titrating racemic warfarin into $\mathrm{BSA}$ in $50 \mathrm{mM}$ phosphate buffer, $\mathrm{pH} 7.4$ in the presence of betaine and L-proline, as well as sorbitol. Two to three ITC titrations were fit globally to a twosite hetero-association model $(\mathrm{A}+\mathrm{B} \leftrightarrows[\mathrm{AB}]+\mathrm{B} \leftrightarrows \mathrm{ABB})$ in SEDPHAT [80]. Crystallographic studies of warfarin binding to human serum albumin have found weak electron density at a second warfarin binding site on serum albumin, and other groups have fit their ITC data to a two site model [81]. The $\mathrm{K}_{\mathrm{d}}$ for the first site is $4.3 \pm 0.8 \mu \mathrm{M}$, which is close to the 3-3.4 $\mu \mathrm{M}$ obtained for racemic warfarin binding to human serum albumin from fluorescence and radio-labelled methods [76, 77]; the $K_{d}$ for the second site has a high error, $58 \pm 38 \mu \mathrm{M}$. There is a 4-fold weakening in binding to the primary warfarin-BSA site when the titrations are performed in $20 \%(\mathrm{w} / \mathrm{v})$ betaine $\left(\mathrm{K}_{\mathrm{d}}=17.9 \pm\right.$ $1.4 \mu \mathrm{M}$ in $20 \%$ betaine). Plots of $\ln \left(\mathrm{K}_{\mathrm{a}}\right)$ versus buffer osmolality for warfarin binding to BSA in the presence of betaine, L-proline and sorbitol are given in Figure 7. The binding of warfarin is weakened by both betaine and L-proline. This result is consistent with our prediction of a weak interaction of betaine or L-proline with unbound warfarin, which shifts the binding equilibrium away from the bound complex towards the unbound species. The $\Delta \mu_{23} / \mathrm{RT}$ values were calculated from the plots of $\ln \left(\mathrm{K}_{\mathrm{a}}\right)$ versus osmolality according to Equation 4; betaine and L-proline show experimental $\Delta \mu_{23} / \mathrm{RT}$ values of - 
$0.75 \pm 0.03$ and $-0.44 \pm 0.03$, respectively. As has been noted by the Record group for a number of small and macro-molecules $[72,74]$, our experimental values for warfarin approximate the predicted values of $-0.52 \pm 0.01$ for betaine and $-0.15 \pm 0.01$ for Lproline (Table 1). Unlike betaine and L-proline, addition of sorbitol increases the affinity of warfarin for BSA. Sorbitol does not appear to associate with free warfarin, which is consistent with our osmometry experiment shown in Figure 6. The different slopes for warfarin binding to BSA are another indication that interactions of the osmolytes with either the ligand and/or the protein are involved [45, 49]. The effects of osmolytes on the second binding site for warfarin could not be accurately measured because the errors in the affinity were too high $(<30 \%)$. According to $C D$, addition of osmolytes did not affect the secondary structure of BSA (data not shown). The thermal stability of BSA measured by DSC increased in the presence of the osmolytes $\left(\Delta \mathrm{T}_{\mathrm{m}}=+3\right.$ to $+6{ }^{\circ} \mathrm{C}$, data not shown), suggesting some degree of osmolyte exclusion from the protein surface. This is a single example of the ability of this approach to predict weaker binding in the presence of osmolytes, however other examples should be examined to determine the wider applicability of this methodology.

As described throughout Section 6, osmolytes can associate with or be excluded from the surfaces of ligands and/or proteins. These various interaction patterns allow general patterns to be discerned for osmolyte effects on binding affinity (Table 2). There are four possible scenarios: 1) exclusion of the osmolyte from both the ligand and protein; 2) exclusion of the osmolyte from the ligand and association with the protein; 3 ) association of the osmolyte with the ligand, but exclusion from the protein; and 4) association of the osmolyte with both ligand and protein. If the osmolyte is excluded from both partners, binding should tighten as the water activity is decreased. Preferential interaction of osmolytes with the ligand, whether or not the osmolyte interacts with the protein, should weaken binding as the osmolyte concentration increases. A more complicated scenario is preferential interaction of the osmolytes with the protein, but exclusion from the ligand. The predicted effects would depend on the relative interaction coefficients and a range of intermediate effects could arise as dehydration effects may be balanced or cancelled by the osmolyte interactions.

\subsection{Crowder Effects on Protein-Protein Interactions}

As the size of the co-solute increases, crowding effects come into play [82-85]. Crowders, primarily large molecules such as PEGs and polymeric saccharides, are inert co-solutes that take up volume in a solution, thus increasing the effective concentration of the ligand and biomacromolecule. From crowding theory, ligand exclusion from the volume occupied by the crowder is due to steric repulsion. By decreasing the effective volume available to the analytes, crowders shift systems towards states with lower entropy and minimum occupied volume [83]. The binding equilibria shift towards the associated states, which will have lower entropy compared to the unbound states [83-85]. For co-solutes of large size, effects on ligand binding are typically noted at lower osmolalities (see, for example, Figure 1 in Sukenik et al. [82]). Though crowders have traditionally been treated as inert, hard bodies when analyzing their effect, recent 
evidence suggests weak, soft, interactions between crowders and analyte molecules that can also effect binding equilibria [86-90].

Pielak and coworkers used ITC to study the effect of mono-, di-, and trisaccharides on complex formation between iso-1-ferricytochrome c $(\mathrm{Cc})$ and ferricytochrome c peroxidase $(\mathrm{CcP})$ from yeast $[91,92]$. Under dilute conditions, and in the presence of mono- and disaccharides, $\mathrm{Cc}$ and $\mathrm{CcP}$ form a 1:1 complex [91]. The effect of crowders on binding was analyzed using several models. Upon the addition of osmolytes, only slight changes in the binding free energy suggested there were not significant waters released upon protein-protein complex formation. This is unexpected as when two protein surfaces interact, water is expected to be released upon complex formation. The authors championed the explanation obtained from excluded volume based analyses, where the crowder and/or protein are considered to be hard, impenetrable spheres, better approximates the change in affinity in the presence of the saccharides than does osmotic stress analysis. Even then the models could only come close to fitting the data, suggesting weak (soft) interactions between the saccharides and the proteins may exist. In another pair of proteins, Phillip et al. found that PEGs cause only minor changes in the affinity of protein-protein association between the K27A mutant of barnase binding to the Y29A barstar [93].

Other macromolecules may also act as crowders. Using folate as an example, as proteins possess and display the motifs seen in osmolytes and as osmolytes can weakly interact with folate, it follows that proteins may also be able to weakly interact with folate. As support for this idea, we note Ringe and Mattos, using the multiple solvent crystal structure approach, have identified small molecule interaction sites in proteins by soaking crystals with organic molecules [94-97]. While these interactions are normally considered to be non-specific and weak, they may modulate function since the in-cell environment is crowded with macromolecules. Some support for many (surprising) binding partners for folate comes from various examples of non-specific folate binding to proteins [98-100] as well as specific binding of folate to the central cavity in hemoglobin [101]. More recently, a mass spec "allosterome" approach searched for metaboliteprotein interactions and found that folate inhibits the apparently unrelated enzymes, glutamate dehydrogenase, glucose 6-phosphate dehydrogenase and NAD kinase [102].

There are a few crowding studies on ligand binding and they typically find that crowder addition either has no effect or tightens ligand binding, similar to osmolyte studies where decreased water activity leads to a lower desolvation penalty (see Table 2 in [103] and Table 1 in [104] for results from 13 enzymes). Small effects on $\mathrm{k}_{\text {cat }}$ can also be seen, often due to excluded volume effects (e.g. crowding) on oligomerization states. A study of hexokinase activity using ITC found addition of BSA as a crowding agent (up to $250 \mathrm{mg} / \mathrm{ml}$ ) slowed $\mathrm{k}_{\mathrm{cat}}$ and weakened the $\mathrm{K}_{\mathrm{m}}$ for glucose by $30 \%$ [105]. The effects were similar such that $\mathrm{k}_{\mathrm{cat}} / \mathrm{K}_{\mathrm{m}}$ was unaffected. In addition, a plot of enthalpy vs BSA concentration was linear, suggesting the involvement of water effects.

\subsection{Competitive Binding Assays}


Both osmolytes and DHFR interact with free DHF, albeit with greatly differing affinities. This would suggest that a competitive binding assay, where a second macromolecule, which also binds DHF, can be added to the solution and the apparent $\mathrm{K}_{\mathrm{d}} \mathrm{s}$ should be weaker than in the absence of the competitor. Competitive binding assays are typically used to examine tight ligand binding by saturating a protein with a weak binding ligand, and titrating in the ligand that binds tightly [106]. In one case, using ITC we found that addition of a weakly interacting protein (e.g. $100 \mu \mathrm{M}$ BSA) affects DHF binding to EcDHFR-NADP ${ }^{+}$[107]. BSA has previously been found to bind folate with low-affinity [108]. In the presence of BSA, the binding of DHF to EcDHFR decreased three-fold using a single site model. Fitting the data globally to a competitive binding model in SEDPHAT [80] $(\mathrm{A}+\mathrm{B}+\mathrm{C} \leftrightarrows \mathrm{AB}+\mathrm{C} \leftrightarrows \mathrm{AC}+\mathrm{B}$, where $\mathrm{B}$ and $\mathrm{C}$ are competitive for $\mathrm{A}$ ) yielded the same ternary complex value for DHF binding to EcDHFR $-\mathrm{NADP}^{+}$as with buffer alone $(=0.35 \mu \mathrm{M})$. A $\mathrm{K}_{\mathrm{d}}$ for DHF binding to BSA was calculated to be $51 \mu \mathrm{M}$, which is 20 -fold tighter than a value previously found by equilibrium dialysis [108]. While this is not a true crowding effect, it provides another view of how weak binding interactions can alter the tight interaction seen in the normal substrateenzyme pair. Also the high concentrations of albumin in blood will allow it to weakly bind a significant fraction of folates.

\subsection{Conclusion}

One consideration when monitoring the effects of co-solutes on a binding interaction is the effect of the co-solutes on the biomacromolecule. Typically, a structural technique, such as circular dichroism, is used to monitor any changes in the secondary structure of the biomacromolecule [54, 55, 62]. If there are changes in the biomacromolecule structure, then these structural changes will also affect the ITC results. Additionally, changes in biomacromolecule stability in the presence of osmolytes can be monitored by DSC $[55,62]$. A decrease in stability of the biomacromolecule in the presence of osmolytes, as was the case with FolM in the presence of DMSO and ethylene glycol [55], will compound the effects associated with changes in water activity incurred by osmolytes. The additional effects on stability of the biomacromolecule make the analysis of the osmotic stress data harder to interpret. Therefore, it is important to monitor effects of co-solutes on biomacromolecule structure and stability in addition to analyzing ITC data.

The role of osmotic stress is of general interest to the scientific community as it begins exploration of the effect co-solutes have on ligand binding. As described in the above experiments, higher concentrations of osmolytes usually tighten binding but there are cases where binding is weakened. Osmotic stress can occur in bacteria, plants which can undergo drought or flooding conditions as well as the mammalian kidney and gut which can endure large variations in osmotic pressure. The production of internal osmolytes or osmoprotectants allows cells to produce molecules that are preferentially excluded from macromolecule surfaces, allowing them to retain their function. Crowding comes into play as the interior of the cell is crowded with many molecules, thus the ability of a ligand to bind to its cognate partner can be impacted. Recent studies of weak 
interactions also suggest they can play an important role in signal transduction, protein stability and drug efficacy [109-112].

Acknowledgements: We thank Lindsay O'Neal for her preliminary BSA-warfarin ITC experiments. We thank our many colleagues in the osmotic stress community for many helpful discussions, including Chris Stanley, Mike Fried, and Don Rau. Funding for this research was provided by the NIH (R15GM110669). The authors acknowledge the Center for Structural Molecular Biology (ERKP291) supported by the U.S. DOE, Office of Science, Office of Biological and Environmental Research and the Scientific User Facilities Division, Basic Energy Sciences. Oak Ridge National Laboratory (ORNL) is managed by UT-Battelle, LLC, for the U. S. Department of Energy (DOE) under contract No. DE-AC05-00OR22725.

\begin{abstract}
Abbreviations: ADP, adenosine diphosphate; APH, aminoglycoside phosphotransferase (3')-IIIa; BSA, bovine serum albumin; Cc, iso-1-ferricytochrome c; CcP, ferricytochrome c peroxidase; $\mathrm{CD}$, circular dichroism; ConA, concanavalin $\mathrm{A} ; \Delta \mathrm{C}_{\mathrm{p}}$, change in heat capacity; $\Delta \mathrm{G}$, Gibbs free energy; $\Delta \mathrm{H}$, enthalpy; $\Delta \mathrm{n}_{\mathrm{w}}$, number of waters released or taken up upon binding; $\Delta \mathrm{S}$, entropy; $\mathrm{D}_{2} \mathrm{O}$, deuterium oxide; DHF, dihydrofolate; DHFR, dihydrofolate reductase; DMSO, dimethylsulfoxide; DSC, differential scanning calorimetry; EcDHFR, chromosomal E. coli dihydrofolate reductase; GK, guanylate kinase; GMP, guanosine monophosphate; HCA, human carbonic anhydrase; ITC, isothermal titration calorimetry; $\mathrm{K}_{\mathrm{a}}$, association constant; $\mathrm{K}_{\mathrm{d}}$, dissociation constant which equals $1 / \mathrm{K}_{\mathrm{a}}$; MTX, methotrexate; MuP, major urinary protein; $\mathrm{NADP}\left({ }^{+} / \mathrm{H}\right)$, nicotinamide adenine dinucleotide phosphate (oxidized/reduced); NMR, nuclear magnetic resonance; PEG, polyethylene glycol; SANS, small angle neutron scattering; T, temperature; TBP, TATA-box binding protein; TEG, triethylene glycol.
\end{abstract}




\section{Table and Figure Captions:}

Table 1. Calculated and experimental $\mu_{23} / \mathrm{RT}$ values for betaine with different ligands. Calculated values used Table 2 in Capp et al. [72]. Experimental values come from Equation 4 and were measured by ITC at $\mathrm{pH} 7.0,25^{\circ} \mathrm{C}$.

Table 2. Predicted effects on binding by the preferential interaction or exclusion of osmolytes from either ligand or protein. Blue shading indicates tighter binding, white indicates no change in affinity, while pink shading signifies weaker binding.

Figure 1. The Born-Haber cycle. A ligand (L) and macromolecule (M) bind in the gas phase, giving the enthalpy intrinsic to the binding contacts made upon complex formation $\left(\Delta \mathrm{H}_{\mathrm{i}}\right.$ top line). The solvation enthalpy of the unbound species $\left(\Delta \mathrm{H}_{\mathrm{S}, \mathrm{U}}\right)$, where $\mathrm{S}$ stands for solvation and $\mathrm{U}$ for unbound species, is shown on the left, while that of the bound complex is shown on the right $\left(\Delta \mathrm{H}_{\mathrm{S}, \mathrm{B}}\right)$, where $\mathrm{B}$ means the bound species. In an actual experiment, the species are already solvated (bottom row) and the observed binding enthalpy $\left(\Delta \mathrm{H}_{\mathrm{obs}}\right)$ includes the change in solvation between the free and bound species in addition to the $\Delta \mathrm{H}_{\mathrm{i}}$.

Figure 2. Models of A) preferential exclusion and B) preferential interaction. The solvation layer of the enzyme is shown in light grey, while the bulk solvent is dark grey. Osmolytes are represented by white ovals.

Figure 3. Ribbon diagram structures showing the ligand binding sites of three unrelated DHFRs. The images show the relative difference in sizes. A) E. coli chromosomal DHFR with bound $\mathrm{NADP}^{+}$and folate (PDB ID: 1RA2) [113]. B) $\mathrm{NADP}^{+}$and DHF bound in the single active site pore formed in the center of the R67 DHFR tetramer (PDB ID: 2RK1) [63]. C) Pteridine reductase from L. major, which is homologous to FolM from E. coli, with NADPH and 10-propargyl-5,8-dideazafolate (CB3717) bound (PDB ID: 2BFA) [114]. Each protomer is shown in a different color. The cofactors are shown in magenta, while the substrate analogues are shown in cyan. Adapted with permission from Bhojane, P. P., Duff, Jr., M. R., Patel, H. C., Vogt, M. E., Howell, E. E., Investigation of osmolyte effects on FolM: Comparison with other dihydrofolate reductases, Biochemistry 53 (2014) 1330-41. Copyright 2014 American Chemical Society.

Figure 4. Plots of $\ln \mathrm{K}_{\mathrm{a}}$ vs osmolality and plots of $\ln \mathrm{k}_{\mathrm{cat}} / \mathrm{K}_{\mathrm{m}}$ vs osmolality. Panel A) addition of betaine tightens binding of NADPH to the 3 different DHFRs (R67 DHFR, O, EcDHFR, $\square$, and FolM, $\triangle$ ) as monitored by ITC. In contrast, betaine weakens binding of DHF to these same 3 structurally diverse DHFRs. Panel B), betaine decreases the enzymatic efficiency of R67 DHFR $(\bigcirc)$ and FolM $(\triangle)$ by increasing the $K_{m}$ of DHF. The slope of the $\ln \left(\mathrm{k}_{\mathrm{cat}} / \mathrm{K}_{\mathrm{m}}\right)$ for DHF plot is similar for both R67 DHFR and FolM. C) Direct measurement of the effect of betaine on DHF binding to the NADP ${ }^{+}$complex of either R67 DHFR (O) or EcDHFR ( $\square$ ) by ITC. Similar slopes are noted for DHF binding to both enzyme complexes. 
Figure 5. A model of the effect of osmolytes associating with DHF on binding to DHFR. In the top portion of the figure, binding occurs in the absence of osmolytes. In the presence of osmolytes $(+)$, water $(*)$ may be replaced from the hydration shell of DHF by osmolyte. When binding is monitored in the presence of osmolytes, both water and osmolytes need to be removed from the ligand surface prior to binding. If the osmolyte interacts more strongly than water with DHF, its removal shifts the binding equilibrium towards the unbound ligand and protein. Adapted with permission from Grubbs, J., Rahmanian, S., DeLuca, A., Padmashali, C., Jackson, M., Duff, Jr., M. R., Howell, E. E., Thermodynamics and solvent effects on substrate and cofactor binding in Escherichia coli chromosomal dihydrofolate reductase, Biochemistry 50 (2011) 3673-85. Copyright 2011 American Chemical Society.

Figure 6. Vapor pressure osmometry experiments to determine the preferential interaction of sorbitol with sodium benzoate, a model soluble aromatic compound. A) Vapor pressure osmometry readings were performed on a Wescor Vapro 5520 for a series of concentrations $(0.1$ to $1.3 \mathrm{~m})$ of sorbitol $(\bigcirc)$ or sorbitol with $0.423 \mathrm{~m}$ benzoate $(\square)$. An osmometry reading for $0.423 \mathrm{~m}$ benzoate alone is also shown $(\mathbf{\Delta})$. Solution osmolalities were measured three times and averaged. B) A plot of the difference in osmolality of the benzoate-sorbitol mixture and the osmolalities of the individual benzoate and sorbitol solutions versus the product of the molalities of benzoate and sorbitol in the mixtures. The slope of the line, fitting the intercept through 0 , gives a preferential interaction coefficient $\left(\mu_{23} / \mathrm{RT}[72]\right)$ of $0.18 \pm 0.02 \mathrm{~m}^{-1}$.

Figure 7. Effect of osmolytes on the binding of racemic warfarin to fatty-acid free BSA in $50 \mathrm{mM} \mathrm{K}_{2} \mathrm{HPO}_{4}, 1 \mathrm{mM}$ EDTA, pH 7.4 at $25{ }^{\circ} \mathrm{C}$. Titration of $1-2 \mathrm{mM}$ warfarin into 10-20 $\mu \mathrm{M}$ BSA was performed in the presence of buffer $(\bigcirc)$, buffer plus betaine $(\bigcirc)$, or sorbitol $(\square)$ or L-proline $(\triangle)$. In some cases, the error bars are smaller than the size of the symbol. Phosphate buffer was used because of its low heat of protonation [115], therefore, protonation effects are not expected to contribute to the thermogram (Duff, Jr., M. R., O’Neal, L., and Howell, E. E. unpublished data). 
Tables:

Table 1.

\begin{tabular}{cccc}
\hline Ligand & Protein & $\begin{array}{c}\text { Experimental } \\
\boldsymbol{\Delta} \boldsymbol{\mu}_{\mathbf{2 3}} / \mathbf{R T}\end{array}$ & $\begin{array}{c}\text { Calculated } \\
\boldsymbol{\mu}_{\mathbf{2} 3} / \mathbf{R T}\end{array}$ \\
\hline DHF & R67 DHFR & $-0.52 \pm 0.01^{\mathrm{a}}$ & $0.13 \pm 0.01$ \\
DHF & EcDHFR & $-0.50 \pm 0.10^{\mathrm{b}}$ & \\
\hline NADPH & R67 DHFR & $0.25 \pm 0.02^{\mathrm{a}}$ & \\
NADPH & EcDHFR & $0.24 \pm 0.10^{\mathrm{b}}$ & $1.11 \pm 0.01$ \\
NADPH & FolM & $0.46 \pm 0.06^{\mathrm{c}}$ & \\
\hline MTX & FolM & $-0.63 \pm 0.12^{\mathrm{c}}$ & $0.01 \pm 0.01$ \\
\hline Warfarin & BSA & $-0.75 \pm 0.03^{\mathrm{d}}$ & $-0.52 \pm 0.01$ \\
\hline
\end{tabular}

${ }^{\mathrm{a}}$ Data from reference [53]. ${ }^{\mathrm{b}}$ Data from reference [54]. ${ }^{\mathrm{c}}$ Values from reference [55]. ${ }^{\mathrm{d}}$ From this paper. 
Table 2.

\begin{tabular}{|c|c|c|c|}
\hline & \multicolumn{2}{|c|}{ Protein } \\
\hline & & $\begin{array}{l}\text { Preferential } \\
\text { Exclusion of } \\
\text { Osmolytes }\end{array}$ & $\begin{array}{c}\text { Preferential } \\
\text { Interaction with } \\
\text { Osmolytes }\end{array}$ \\
\hline $\bar{\Xi}$ & 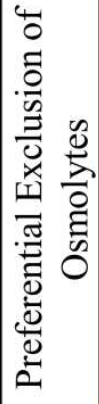 & $\begin{array}{l}\text { Tighter Binding } \\
\text { Ex. NADPH } \\
\text { binding to R67 } \\
\text { DHFR [3] }\end{array}$ & $\begin{array}{l}\text { Variable Effects } \\
\text { Depending upon } \\
\text { Protein-Osmolyte } \\
\text { Interactions } \\
\text { Ex. NADPH } \\
\text { binding to } \\
\text { EcDHFR [4] }\end{array}$ \\
\hline ב & 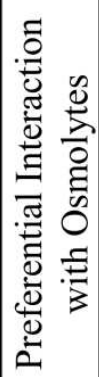 & $\begin{array}{l}\text { Weaker Binding } \\
\text { Ex. DHF binding } \\
\text { to R67 DHFR [3]; } \\
\text { Warfarin binding } \\
\text { to BSA }\end{array}$ & $\begin{array}{l}\text { Variable Effects to } \\
\text { Weaker Binding } \\
\text { Ex. DHF binding } \\
\text { to EcDHFR and } \\
\text { FolM }[4,5]\end{array}$ \\
\hline
\end{tabular}




\section{References}

[1] A. Velazquez-Campoy, M. J. Todd, E. Freire, HIV-1 protease inhibitors: enthalpic versus entropic optimization of the binding affinity, Biochemistry 39 (2000) 2201-7.

[2] Z. Lin, F. P. Schwartz, E. Eisenstein, The hydrophobic nature of GroEL-substrate binding, J. Biol. Chem. 270 (1995) 1011-4.

[3] D. Chandler, Interfaces and the driving force of hydrophobic assembly, Nature 437 (2005) 640-7.

[4] A. J. Patel, P. Varilly, S. N. Jamadagni, M. F. Hagan, D. Chandler, S. Garde, Sitting at the edge: how biomolecules use hydrophobicity to tune their interactions and function, J. Phys. Chem. B 116 (2012) 2498-503.

[5] A. Biela, M. Betz, A. Heine, G. Klebe, Water makes the difference: rearrangement of water solvation layer triggers non-additivity of functional group contributions in proteinligand binding, ChemMedChem 7 (2012) 1423-34.

[6] A. Biela, N. N. Nasief, M. Betz, A. Heine, D. Hangauer, G. Klebe, Dissecting the hydrophobic effect on the molecular level: the role of water, enthalpy, and entropy in ligand binding to thermolysin, Angew. Chem. Int. Ed. Engl. 52 (2013) 1822-8.

[7] S. G. Krimmer, M. Betz, A. Heine, G. Klebe, Methyl, ethyl, propyl, butyl: futile but not for water, as the correlation of structure and thermodynamic signature shows in a congeneric series of thermolysin inhibitors, ChemMedChem 9 (2014) 833-46.

[8] B. Breiten, M. R. Lockett, W. Sherman, S. Fujita, M. Al-Sayah, H. Lange, C. M. Bowers, A. Heroux, G. Krilov, G. M. Whitesides, Water networks contribute to enthalpy/entropy compensation in protein-ligand binding, J. Am. Chem. Soc. 135 (2013) 15579-84.

[9] P. W. Snyder, J. Mecinovic, D. T. Moustakas, S. W. Thomas, 3rd, M. Harder, E. T. Mack, M. R. Lockett, A. Heroux, W. Sherman, G. M. Whitesides, Mechanism of the hydrophobic effect in the biomolecular recognition of arylsulfonamides by carbonic anhydrase, Proc. Natl. Acad. Sci. U. S. A. 108 (2011) 17889-94.

[10] M. R. Lockett, H. Lange, B. Breiten, A. Heroux, W. Sherman, D. Rappoport, P. O. Yau, P. W. Snyder, G. M. Whitesides, The binding of benzoarylsulfonamide ligands to human carbonic anhydrase is insensitive to formal fluorination of the ligand, Angew. Chem. Int. Ed. Engl. 52 (2013) 7714-7.

[11] S. W. Homans, Water, water everywhere--except where it matters?, Drug Discov. Today 12 (2007) 534-9.

[12] N. Shimokhina, A. Bronowska, S. W. Homans, Contribution of ligand desolvation to binding thermodynamics in a ligand-protein interaction, Angew. Chem. Int. Ed. Engl. 45 (2006) 6374-6.

[13] R. Malham, S. Johnstone, R. J. Bingham, E. Barratt, S. E. Phillips, C. A. Laughton, S. W. Homans, Strong solute-solute dispersive interactions in a protein-ligand complex, J. Am. Chem. Soc. 127 (2005) 17061-7.

[14] R. J. Bingham, J. B. Findlay, S. Y. Hsieh, A. P. Kalverda, A. Kjellberg, C. Perazzolo, S. E. Phillips, K. Seshadri, C. H. Trinh, W. B. Turnbull, G. Bodenhausen, S. W. Homans, Thermodynamics of binding of 2-methoxy-3-isopropylpyrazine and 2methoxy-3-isobutylpyrazine to the major urinary protein, J. Am. Chem. Soc. 126 (2004) $1675-81$. 
[15] N. R. Syme, C. Dennis, A. Bronowska, G. C. Paesen, S. W. Homans, Comparison of entropic contributions to binding in a "hydrophilic" versus "hydrophobic" ligand-protein interaction, J. Am. Chem. Soc. 132 (2010) 8682-9.

[16] T. Young, R. Abel, B. Kim, B. J. Berne, R. A. Friesner, Motifs for molecular recognition exploiting hydrophobic enclosure in protein-ligand binding, Proc. Natl. Acad. Sci. U. S. A. 104 (2007) 808-13.

[17] J. Qvist, M. Davidovic, D. Hamelberg, B. Halle, A dry ligand-binding cavity in a solvated protein, Proc. Natl. Acad. Sci. U. S. A. 105 (2008) 6296-301.

[18] W. P. Jencks, On the attribution and additivity of binding energies, Proc. Natl. Acad. Sci. U. S. A. 78 (1981) 4046-50.

[19] A. Ben-Naim, Hydrophobic interaction and structural changes in the solvent, Biopolymers 14 (1975) 1337-55.

[20] H.-A. Yu, M. Karplus, A thermodynamic analysis of solvation J. Chem. Phys. 89 (1988) 2366-79.

[21] C. Frisch, G. Schreiber, C. M. Johnson, A. R. Fersht, Thermodynamics of the interaction of barnase and barstar: changes in free energy versus changes in enthalpy on mutation, J. Mol. Biol. 267 (1997) 696-706.

[22] J. M. Sturtevant, Heat capacity and entropy changes in processes involving proteins, Proc. Natl. Acad. Sci. U. S. A. 74 (1977) 2236-40.

[23] R. S. Spolar, M. T. Record, Jr., Coupling of local folding to site-specific binding of proteins to DNA, Science 263 (1994) 777-84.

[24] N. V. Prabhu, K. A. Sharp, Heat capacity in proteins, Annu. Rev. Phys. Chem. 56 (2005) 521-48.

[25] A. Cooper, Heat capacity effects in protein folding and ligand binding: a reevaluation of the role of water in biomolecular thermodynamics, Biophys. Chem. 115 (2005) 89-97.

[26] G. A. Holdgate, A. Tunnicliffe, W. H. Ward, S. A. Weston, G. Rosenbrock, P. T. Barth, I. W. Taylor, R. A. Pauptit, D. Timms, The entropic penalty of ordered water accounts for weaker binding of the antibiotic novobiocin to a resistant mutant of DNA gyrase: a thermodynamic and crystallographic study, Biochemistry 36 (1997) 9663-73. [27] M. Bello, G. Perez-Hernandez, D. A. Fernandez-Velasco, R. Arreguin-Espinosa, E. Garcia-Hernandez, Energetics of protein homodimerization: effects of water sequestering on the formation of beta-lactoglobulin dimer, Proteins 70 (2008) 1475-87.

[28] C. M. Stegmann, D. Seeliger, G. M. Sheldrick, B. L. de Groot, M. C. Wahl, The thermodynamic influence of trapped water molecules on a protein-ligand interaction, Angew. Chem. Int. Ed. Engl. 48 (2009) 5207-10.

[29] S. Bergqvist, M. A. Williams, R. O'Brien, J. E. Ladbury, Heat capacity effects of water molecules and ions at a protein-DNA interface, J. Mol. Biol. 336 (2004) 829-42. [30] K. M. Peterson, K. V. Gopalan, A. Nandy, D. K. Srivastava, Influence of Glu-376 -$>$ Gln mutation on enthalpy and heat capacity changes for the binding of slightly altered ligands to medium chain acyl-CoA dehydrogenase, Protein Sci. 10 (2001) 1822-34.

[31] S. M. Habermann, K. P. Murphy, Energetics of hydrogen bonding in proteins: a model compound study, Protein Sci. 5 (1996) 1229-39.

[32] M. C. Chervenak, E. J. Toone, A direct measure of the contribution of solvent reorganization to the enthalpy of binding, J. Am. Chem. Soc. 116 (1994) 10533-39. 
[33] T. G. Oas, E. J. Toone, Thermodynamic solvent isotope effects and molecular hydrophobicity, Adv. Biophysics 6 (1997) 1-52.

[34] G. Némethy, H. A. Scheraga, Structure of water and hydrophobic bonding in proteins. IV. The thermodynamic properties of liquid deuterium oxide, J. Chem. Phys. 41 (1964) 680-9

[35] Y. Marcus, A. Ben-Naim, A study of the structure of water and its dependence on solutes based on the isotope effects on solvation thermodynamics in water, J. Chem. Phys. 83 (1985) 4744-59.

[36] G. E. Walrafen, in: F. Franks (Eds.), Water: A Comprehensive Treatise, Plenum Press, New York, 1972, pp. 151.

[37] M. Sobhany, J. Dong, M. Negishi, Two-step mechanism that determines the donor binding specificity of human UDP-N-acetylhexosaminyltransferase, J. Biol. Chem. 280 (2005) 23441-5.

[38] T. K. Dam, S. Oscarson, J. C. Sacchettini, C. F. Brewer, Differential solvation of "core" trimannoside complexes of the Dioclea grandiflora lectin and concanavalin A detected by primary solvent isotope effects in isothermal titration microcalorimetry, J. Biol .Chem. 273 (1998) 32826-32.

[39] C. Ozen, A. L. Norris, M. L. Land, E. Tjioe, E. H. Serpersu, Detection of specific solvent rearrangement regions of an enzyme: NMR and ITC studies with aminoglycoside phosphotransferase(3')-IIIa, Biochemistry 47 (2008) 40-9.

[40] E. H. Serpersu, A. L. Norris, Effect of protein dynamics and solvent in ligand recognition by promiscuous aminoglycoside-modifying enzymes, Adv. Carbohydr. Chem. Biochem. 67 (2012) 221-48.

[41] M. J. Timson, M. R. Duff, Jr. , G. Dickey, A. M. Saxton, J. Reyes-De-Corcuera, E. E. Howell, Further Studies on the Role of Water in R67 Dihydrofolate Reductase, Biochemistry 52 (2013) 2118-27.

[42] C. Eginton, D. Beckett, A large solvent isotope effect on protein association thermodynamics, Biochemistry 52 (2013) 6595-600.

[43] Y. Shi, S. Wang, S. Krueger, F. P. Schwarz, Effect of mutations at the monomermonomer interface of cAMP receptor protein on specific DNA binding, J. Biol. Chem. 274 (1999) 6946-56.

[44] P. R. Connelly, J. A. Thomson, M. J. Fitzgibbon, F. J. Bruzzese, Probing hydration contributions to the thermodynamics of ligand binding by proteins. Enthalpy and heat capacity changes of tacrolimus and rapamycin binding to FK506 binding protein in $\mathrm{D}_{2} \mathrm{O}$ and $\mathrm{H}_{2} \mathrm{O}$, Biochemistry 32 (1993) 5583-90.

[45] E. S. Courtenay, M. W. Capp, C. F. Anderson, M. T. Record, Jr., Vapor pressure osmometry studies of osmolyte-protein interactions: implications for the action of osmoprotectants in vivo and for the interpretation of "osmotic stress" experiments in vitro, Biochemistry 39 (2000) 4455-71.

[46] V. A. Parsegian, R. P. Rand, D. C. Rau, Macromolecules and water: probing with osmotic stress, Methods Enzymol. 259 (1995) 43-94.

[47] D. Harries, D. C. Rau, V. A. Parsegian, Solutes probe hydration in specific association of cyclodextrin and adamantane, J. Am. Chem. Soc. 127 (2005) 2184-90. [48] C. Stanley, S. Krueger, V. A. Parsegian, D. C. Rau, Protein structure and hydration probed by SANS and osmotic stress, Biophys. J. 94 (2008) 2777-89. 
[49] S. N. Timasheff, Protein-solvent preferential interactions, protein hydration, and the modulation of biochemical reactions by solvent components, Proc. Natl. Acad. Sci. U. S. A. 99 (2002) 9721-6.

[50] M. G. Fried, D. F. Stickle, K. V. Smirnakis, C. Adams, D. MacDonald, P. Lu, Role of hydration in the binding of lac repressor to DNA, J. Biol. Chem. 277 (2002) 50676-82. [51] T. V. Chalikian, Structural thermodynamics of hydration, J. Phys. Chem. B 105 (2001) 12566-78.

[52] S. Bergqvist, R. O'Brien, J. E. Ladbury, Site-specific cation binding mediates TATA binding protein-DNA interaction from a hyperthermophilic archaeon, Biochemistry 40 (2001) 2419-25.

[53] S. Chopra, R. Dooling, C. G. Horner, E. E. Howell, A balancing act: Net uptake of water during dihydrofolate binding and net release of water upon NADPH binding in R67 dihydrofolate reductase, J. Biol. Chem. 283 (2008) 4690-8.

[54] J. Grubbs, S. Rahmanian, A. DeLuca, C. Padmashali, M. Jackson, M. R. Duff, Jr., E. E. Howell, Thermodynamics and solvent effects on substrate and cofactor binding in Escherichia coli chromosomal dihydrofolate reductase, Biochemistry 50 (2011) 3673-85. [55] P. P. Bhojane, M. R. Duff, Jr., H. C. Patel, M. E. Vogt, E. E. Howell, Investigation of osmolyte effects on FolM: comparison with other dihydrofolate reductases, Biochemistry 53 (2014) 1330-41.

[56] V. J. LiCata, N. M. Allewell, Functionally linked hydration changes in Escherichia coli aspartate transcarbamylase and its catalytic subunit, Biochemistry 36 (1997) 101617.

[57] G. D. Dzingeleski, R. Wolfenden, Hypersensitivity of an enzyme reaction to solvent water, Biochemistry 32 (1993) 9143-7.

[58] J. A. Kornblatt, M. J. Kornblatt, G. H. Hoa, A. G. Mauk, Responses of two proteinprotein complexes to solvent stress: does water play a role at the interface?, Biophys. J. 65 (1993) 1059-65.

[59] Y. Furukawa, I. Morishima, The role of water molecules in the association of cytochrome P450cam with putidaredoxin. An osmotic pressure study, J. Biol. Chem. 276 (2001) 12983-90.

[60] T. N. Bhat, G. A. Bentley, G. Boulot, M. I. Greene, D. Tello, W. Dall'Acqua, H. Souchon, F. P. Schwarz, R. A. Mariuzza, R. J. Poljak, Bound water molecules and conformational stabilization help mediate an antigen-antibody association, Proc. Natl. Acad. Sci. U. S. A. 91 (1994) 1089-93.

[61] K. A. Xavier, K. A. Shick, S. J. Smith-Gil, R. C. Willson, Involvement of water molecules in the association of monoclonal antibody HyHEL-5 with bobwhite quail lysozyme, Biophys. J. 73 (1997) 2116-25.

[62] C. P. Swaminathan, A. Nandi, S. S. Visweswariah, A. Surolia, Thermodynamic analyses reveal role of water release in epitope recognition by a monoclonal antibody against the human guanylyl cyclase C receptor, J. Biol. Chem. 274 (1999) 31272-8. [63] J. M. Krahn, M. R. Jackson, E. F. DeRose, E. E. Howell, R. E. London, Crystal structure of a type II dihydrofolate reductase catalytic ternary complex, Biochemistry 46 (2007) 14878-88.

[64] N. Y. Sidorova, D. C. Rau, The dissociation rate of the EcoRI-DNA-specific complex is linked to water activity, Biopolymers 53 (2000) 363-8. 
[65] L. R. Singh, N. K. Poddar, T. A. Dar, R. Kumar, F. Ahmad, Protein and DNA destabilization by osmolytes: The other side of the coin, Life Sci. 88 (2011) 117-25. [66] M. M. Santoro, Y. F. Liu, S. M. A. Khan, L. X. Hou, D. W. Bolen, Increased Thermal-Stability of Proteins in the Presence of Naturally-Occurring Osmolytes, Biochemistry 31 (1992) 5278-83.

[67] A. Torreggiani, M. Di Foggia, I. Manco, A. De Maio, S. A. Markarian, S. Bonora, Effect of sulfoxides on the thermal denaturation of hen lysozyme: A calorimetric and Raman study, J. Mol. Struct. 891 (2008) 115-22.

[68] Z. R. W. Yang, S. W. Tendian, W. M. Carson, W. J. Brouillette, L. J. Delucas, C. G. Brouillette, Dimethyl sulfoxide at $2.5 \%(\mathrm{v} / \mathrm{v})$ alters the structural cooperativity and unfolding mechanism of dimeric bacterial NAD(+) synthetase, Protein Sci. 13 (2004) 830-41.

[69] S. Diamant, N. Eliahu, D. Rosenthal, P. Goloubinoff, Chemical chaperones regulate molecular chaperones in vitro and in cells under combined salt and heat stresses, J. Biol. Chem. 276 (2001) 39586-91.

[70] P. Wu, D. W. Bolen, Osmolyte-induced protein folding free energy changes, Proteins 63 (2006) 290-96.

[71] S. Belluzo, V. Boeris, B. Farruggia, G. Pico, Influence of stabilizers cosolutes on catalase conformation, Int. J. Biol. Macromol. 49 (2011) 936-41.

[72] M. W. Capp, L. M. Pegram, R. M. Saecker, M. Kratz, D. Riccardi, T. Wendorff, J.

G. Cannon, M. T. Record, Jr., Interactions of the osmolyte glycine betaine with molecular surfaces in water: thermodynamics, structural interpretation, and prediction of m-values, Biochemistry 48 (2009) 10372-9.

[73] E. J. Guinn, L. M. Pegram, M. W. Capp, M. N. Pollock, M. T. Record, Jr., Quantifying why urea is a protein denaturant, whereas glycine betaine is a protein stabilizer, Proc. Natl. Acad. Sci. U. S. A. 108 (2011) 16932-7.

[74] R. C. Diehl, E. J. Guinn, M. W. Capp, O. V. Tsodikov, M. T. Record, Jr., Quantifying additive interactions of the osmolyte proline with individual functional groups of proteins: comparisons with urea and glycine betaine, interpretation of $\mathrm{m}$ values, Biochemistry 52 (2013) 5997-6010.

[75] V. A. Parsegian, R. P. Rand, D. C. Rau, Osmotic stress, crowding, preferential hydration, and binding: A comparison of perspectives, Proc. Natl. Acad. Sci. U. S. A. 97 (2000) 3987-92.

[76] D. E. Epps, T. J. Raub, F. J. Kezdy, A general, wide-rage spectrofluorometric method for measuring the site-specific affinities of drugs toward human serum albumin, Anal. Biochem. 227 (1995) 342-50.

[77] H. M. Solomon, J. J. Schrogie, D. Williams, The displacement of phenylbutazone$14 \mathrm{C}$ and warfarin-14C from human albumin by various drugs and fatty acids, Biochem. Pharmacol. 17 (1968) 143-51.

[78] M. Fasano, S. Curry, E. Terreno, M. Galliano, G. Fanali, P. Narciso, S. Notari, P. Ascenzi, The extraordinary ligand binding properties of human serum albumin, IUBMB Life 57 (2005) 787-96.

[79] I. Petitpas, A. A. Bhattacharya, S. Twine, M. East, S. Curry, Crystal structure analysis of warfarin binding to human serum albumin: anatomy of drug site I, J. Biol. Chem. 276 (2001) 22804-9. 
[80] J. C. Houtman, P. H. Brown, B. Bowden, H. Yamaguchi, E. Appella, L. E.

Samelson, P. Schuck, Studying multisite binary and ternary protein interactions by global analysis of isothermal titration calorimetry data in SEDPHAT: application to adaptor protein complexes in cell signaling, Protein Sci. 16 (2007) 30-42.

[81] J. L. Perry, M. R. Goldsmith, T. R. Williams, K. P. Radack, T. Christensen, J. Gorham, M. A. Pasquinelli, E. J. Toone, D. N. Beratan, J. D. Simon, Binding of warfarin influences the acid-base equilibrium of $\mathrm{H} 242$ in sudlow site I of human serum albumin, Photochem. Photobiol. 82 (2006) 1365-9.

[82] S. Sukenik, L. Sapir, D. Harries, Balance of enthalpy and entropy in depletion forces, Curr. Opin. Colloid Interface Sci. 18 (2013) 495-501.

[83] H. X. Zhou, G. Rivas, A. P. Minton, Macromolecular crowding and confinement:

biochemical, biophysical, and potential physiological consequences, Annu. Rev. Biophys. 37 (2008) 375-97.

[84] S. B. Zimmerman, A. P. Minton, Macromolecular crowding: biochemical, biophysical, and physiological consequences, Annu. Rev. Biophys. Biomol. Struct. 22 (1993) 27-65.

[85] R. J. Ellis, Macromolecular crowding: an important but neglected aspect of the intracellular environment, Curr. Opin. Struct. Biol. 11 (2001) 114-9.

[86] S. Sukenik, R. Politi, L. Ziserman, D. Danino, A. Friedler, D. Harries, Crowding alone cannot account for cosolute effect on amyloid aggregation, PLoS One 6 (2011) e15608.

[87] S. Sukenik, L. Sapir, R. Gilman-Politi, D. Harries, Diversity in the mechanisms of cosolute action on biomolecular processes, Faraday Discuss. 160 (2013) 225-37. [88] A. C. Miklos, C. Li, N. G. Sharaf, G. J. Pielak, Volume exclusion and soft interaction effects on protein stability under crowded conditions, Biochemistry 49 (2010) 6984-91.

[89] M. Sarkar, C. Li, G. J. Pielak, Soft interactions and crowding, Biophys. Rev. 5 (2013) 187-94.

[90] R. Gilman-Politi, D. Harries, Unraveling the molecular mechanism of enthalpy driven peptide folding by polyol osmolytes, J. Chem. Theory Comput. 7 (2011) 3816-28. [91] A. S. Morar, X. Wang, G. J. Pielak, Effects of crowding by mono-, di-, and tetrasaccharides on cytochrome c-cytochrome c peroxidase binding: comparing experiment to theory, Biochemistry 40 (2001) 281-5.

[92] A. S. Morar, G. J. Pielak, Crowding by trisaccharides and the 2:1 cytochrome ccytochrome c peroxidase complex, Biochemistry 41 (2002) 547-51.

[93] Y. Phillip, E. Sherman, G. Haran, G. Schreiber, Common crowding agents have only a small effect on protein-protein interactions, Biophys. J. 97 (2009) 875-85.

[94] C. Mattos, C. R. Bellamacina, E. Peisach, A. Pereira, D. Vitkup, G. A. Petsko, D.

Ringe, Multiple solvent crystal structures: probing binding sites, plasticity and hydration, J. Mol. Biol. 357 (2006) 1471-82.

[95] C. Mattos, D. Ringe, Proteins in organic solvents, Curr. Opin. Struct. Biol. 11 (2001) 761-4.

[96] D. Ringe, What makes a binding site a binding site?, Curr. Opin. Struct. Biol. 5 (1995) 825-9.

[97] M. Dechene, G. Wink, M. Smith, P. Swartz, C. Mattos, Multiple solvent crystal structures of ribonuclease A: an assessment of the method, Proteins 76 (2009) 861-81. 
[98] F. Fernandes-Costa, J. Metz, Role of serum folate binders in the delivery of folate to tissues and to the fetus, Br. J. Haematol. 41 (1979) 335-42.

[99] R. De Wit, R. Bulgakov, Guanine nucleotides modulate the ligand binding properties of cell surface folate receptors in Dictyostelium discoideum, FEBS Lett. 179 (1985) 25761.

[100] R. Corrocher, G. De Sandre, A. Ambrosetti, M. L. Pachor, L. M. Bambara, A. V. Hoffbrand, Specific and non-specific folate binding protein in normal and malignant human tissues, J. Clin. Pathol. 31 (1978) 659-65.

[101] A. Arnone, P. H. Rogers, R. E. Benesch, R. Benesch, S. Kwong, The interaction of folylpolyglutamates with deoxyhemoglobin. Identification of the binding site, J. Biol. Chem. 261 (1986) 5853-7.

[102] T. Orsak, T. L. Smith, D. Eckert, J. E. Lindsley, C. R. Borges, J. Rutter, Revealing the Allosterome: Systematic Identification of Metabolite-Protein Interactions, Biochemistry 51 (2012) 225-32.

[103] T. Vopel, G. I. Makhatadze, Enzyme activity in the crowded milieu, PLoS One 7 (2012) e39418.

[104] M. G. Norris, N. Malys, What is the true enzyme kinetics in the biological system? An investigation of macromolecular crowding effect upon enzyme kinetics of glucose-6phosphate dehydrogenase, Biochem. Biophys. Res. Commun. 405 (2011) 388-92.

[105] S. N. Olsen, Applications of isothermal titration calorimetry to measure enzyme kinetics and activity in complex solutions, Thermochim. Acta 448 (2006) 12-8.

[106] A. Velazquez-Campoy, E. Freire, Isothermal titration calorimetry to determine association constants for high-affinity ligands, Nat. Protoc. 1 (2006) 186-91.

[107] M. R. Duff, Jr., J. Grubbs, E. Serpersu, E. E. Howell, Weak interactions between folate and osmolytes in solution, Biochemistry 51 (2012) 2309-18.

[108] A. Zettner, P. E. Duly, The weak binding reaction between folate and human serum proteins, Ann. Clin. Lab. Sci. 8 (1978) 57-63.

[109] Q. Wang, A. Zhuravleva, L. M. Gierasch, Exploring weak, transient protein-protein interactions in crowded in vivo environments by in-cell nuclear magnetic resonance spectroscopy, Biochemistry 50 (2011) 9225-36.

[110] M. Sarkar, G. J. Pielak, An osmolyte mitigates the destabilizing effect of protein crowding, Protein Sci. 23 (2014) 1161-64.

[111] Q. Xing, P. Huang, J. Yang, J.-Q. Sun, Z. Gong, X. Dong, D.-C. Guo, S.-M. Chen, Y.-H. Yang, Y. Wang, M.-H. Yang, M. Yi, Y.-M. Ding, M.-L. Liu, W.-P. Zhang, C. Tang, Visualizing and ultra-weak protein-protein interaction in phosphorylation signaling, Angew. Chem. Int. Ed. Engl. 126 (2014) 11685-9.

[112] D. A. Smith, L. Di, E. H. Kerns, The effect of plasma protein binding on in vivo efficacy: misconceptions in drug discovery, Nat Rev Drug Discov 9 (2010) 929-39. [113] M. R. Sawaya, J. Kraut, Loop and subdomain movements in the mechanism of Escherichia coli dihydrofolate reductase: crystallographic evidence, Biochemistry 36 (1997) 586-603.

[114] A. W. Schuttelkopf, L. W. Hardy, S. M. Beverley, W. N. Hunter, Structures of Leishmania major pteridine reductase complexes reveal the active site features important for ligand binding and to guide inhibitor design, J. Mol. Biol. 352 (2005) 105-16. 
[115] H. Fukada, K. Takahashi, Enthalpy and heat capacity changes for the proton dissociation of various buffer components in $0.1 \mathrm{M}$ potassium chloride, ProteinsStructure Function and Genetics 33 (1998) 159-66. 


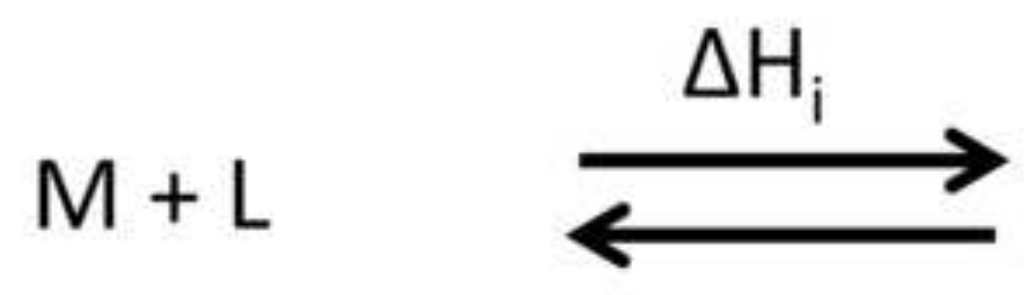

\section{$M \bullet L$}

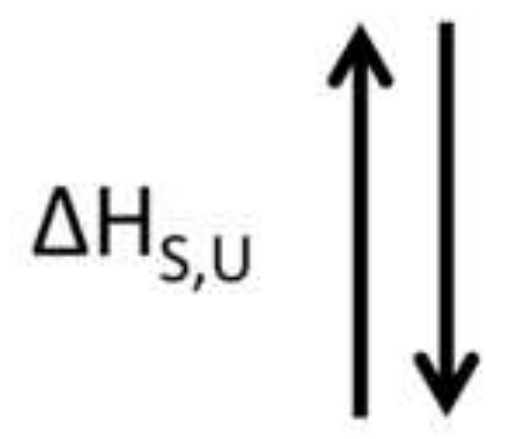

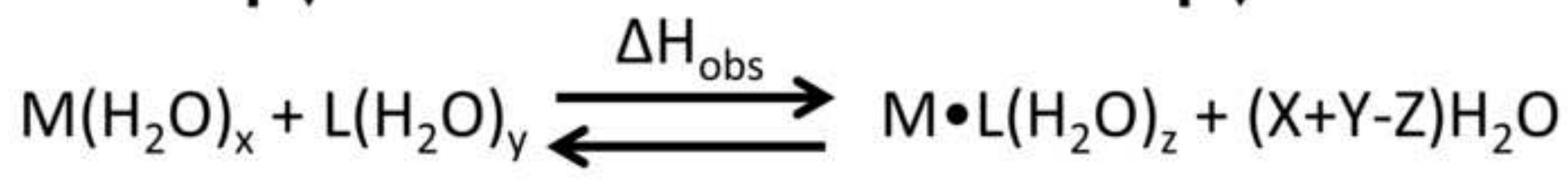

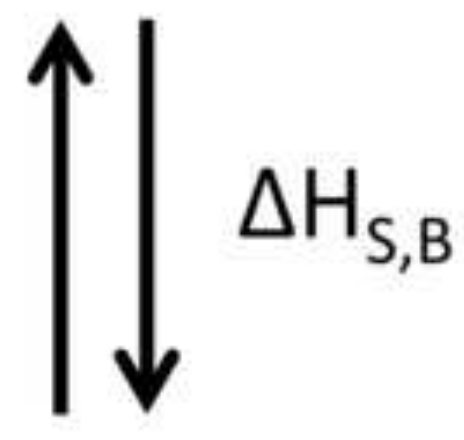


A)

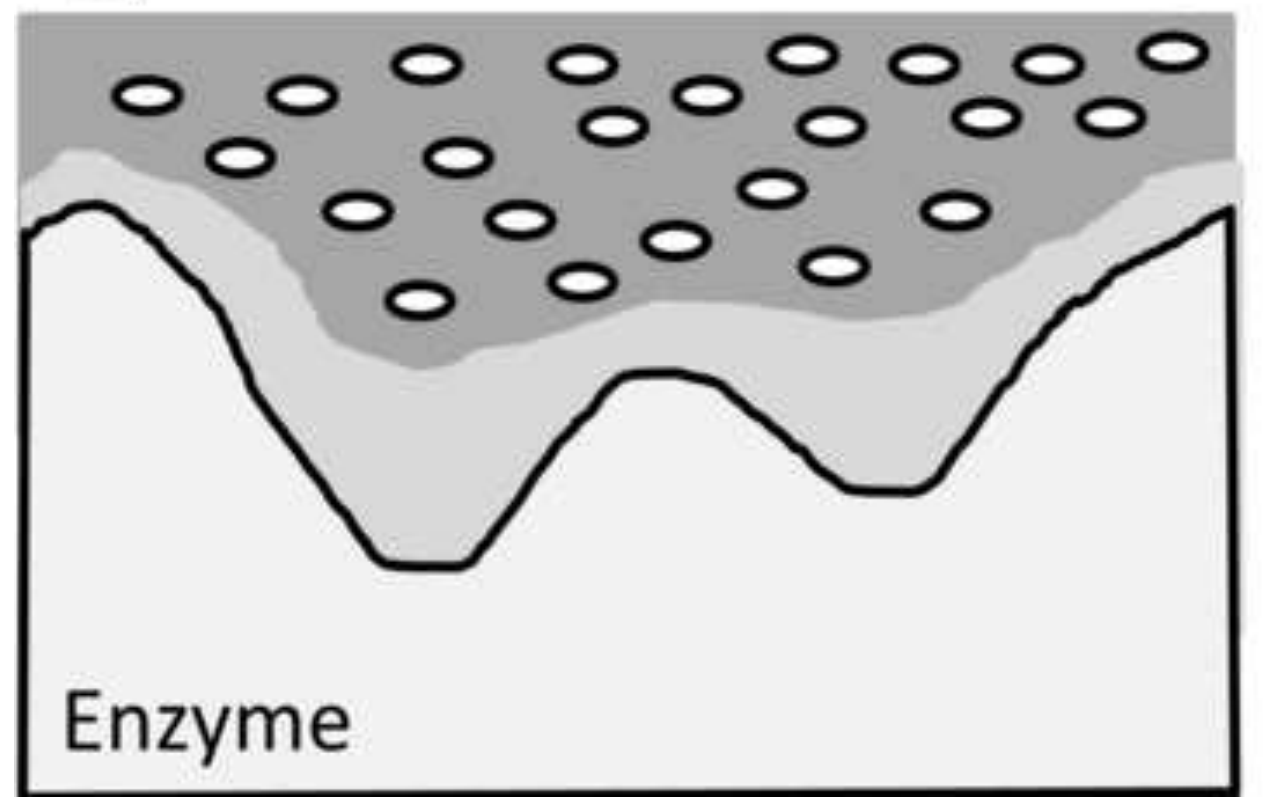

B)

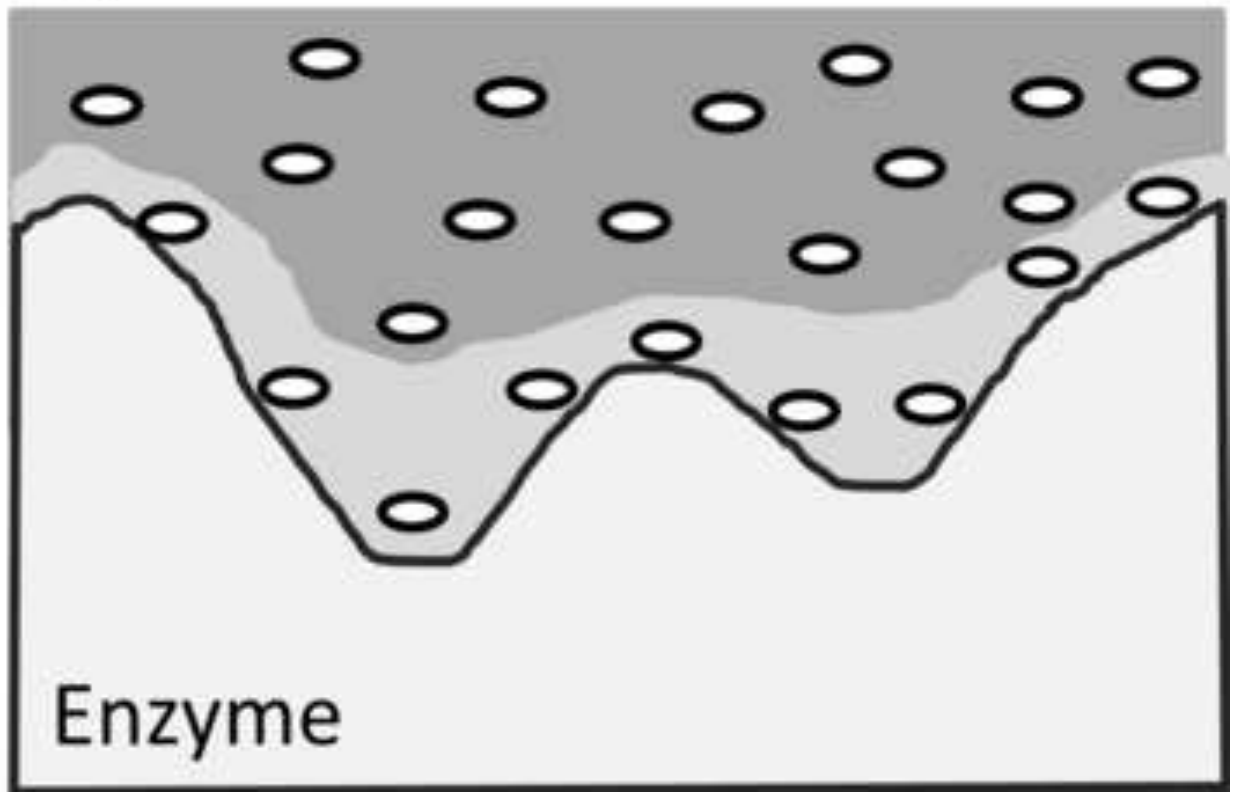


A)

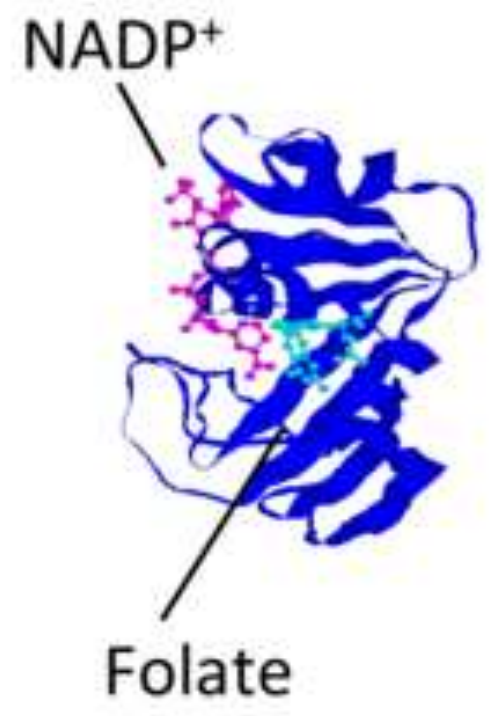

ECDHFR
B)

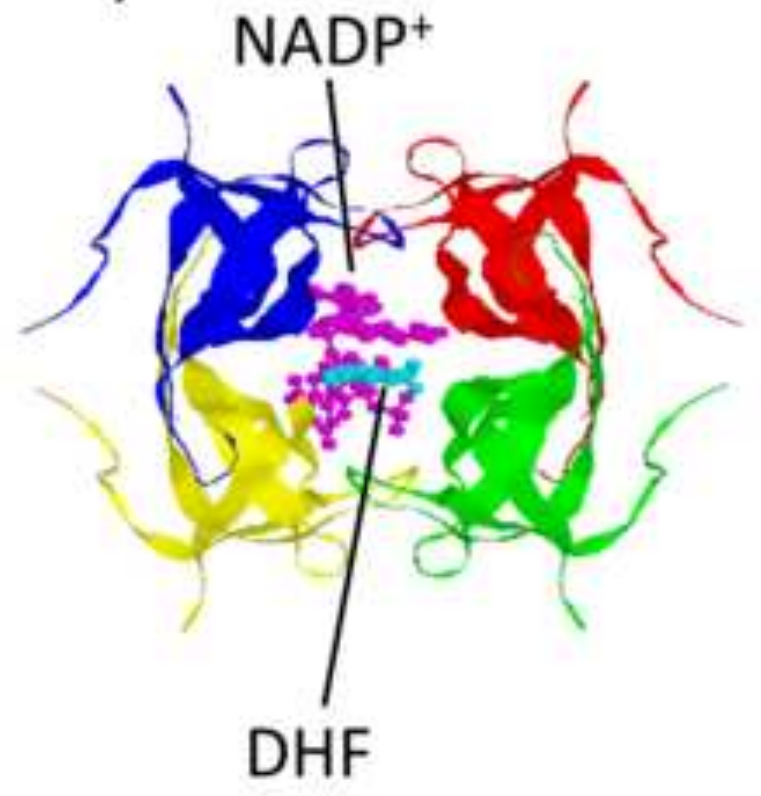

R67 DHFR
C)

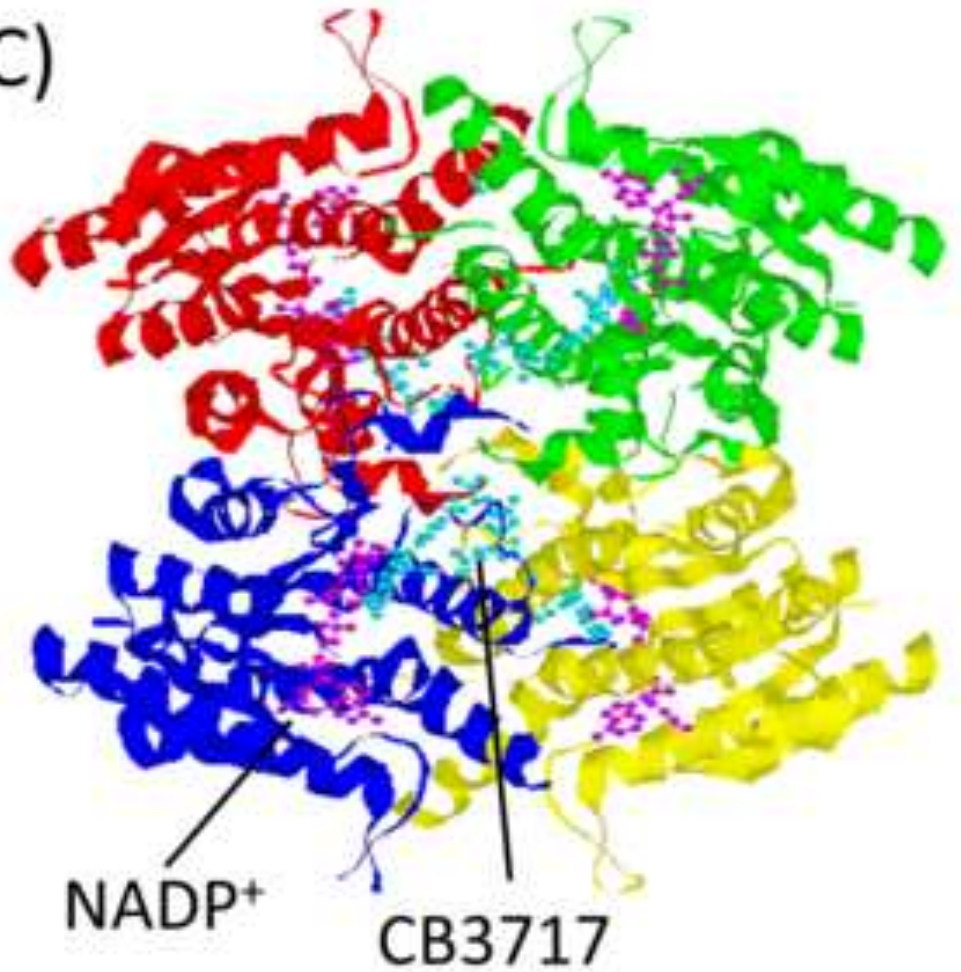

PTR1 
Figure
Click here to download high resolution image

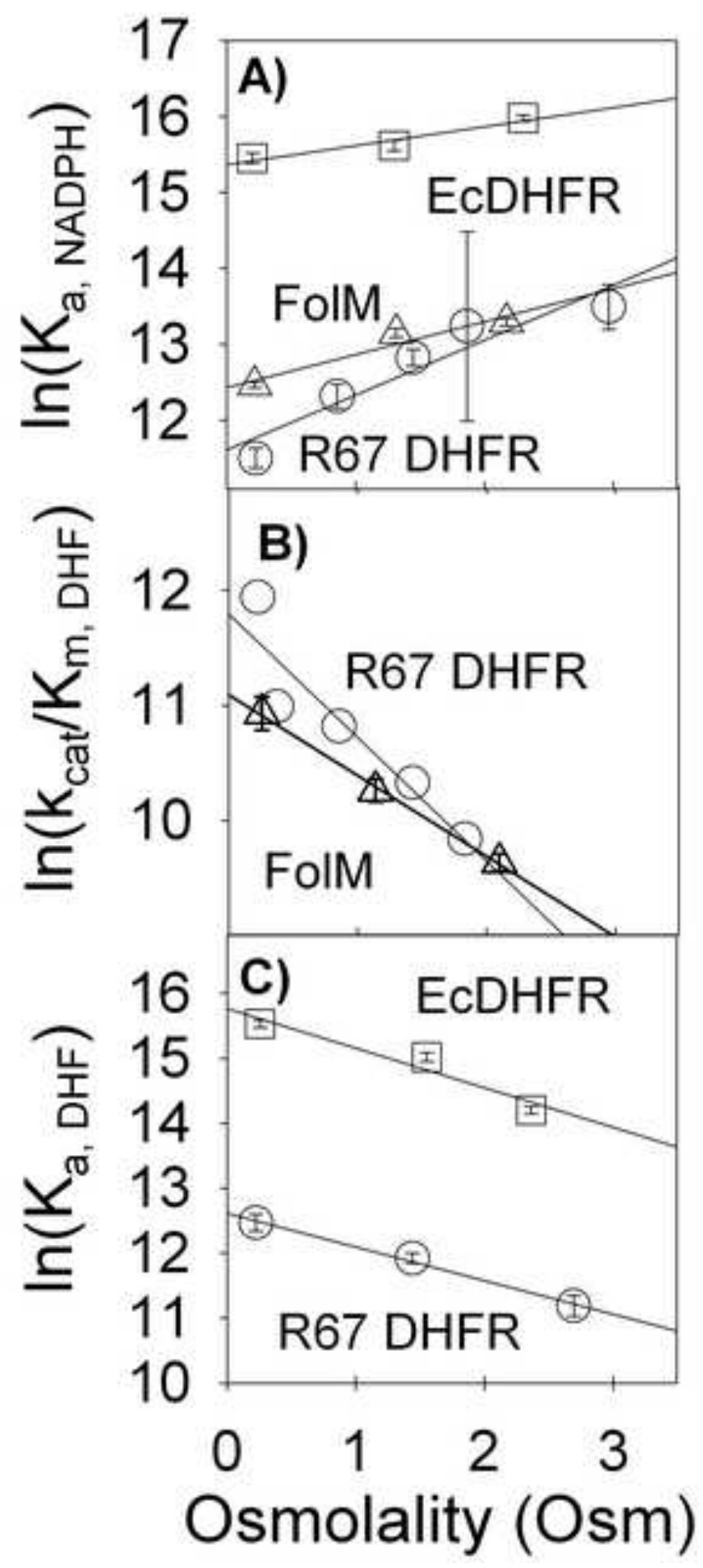



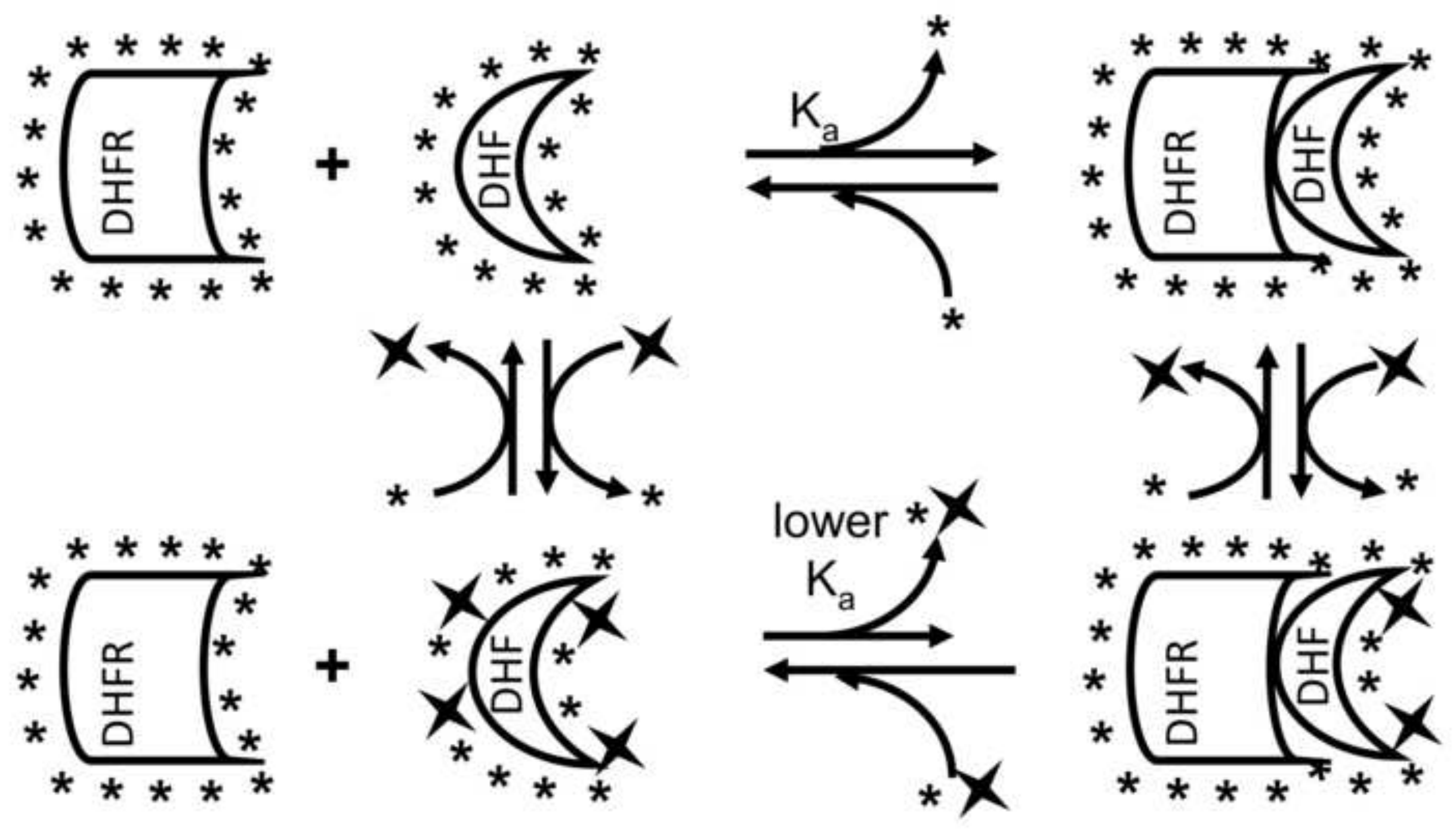


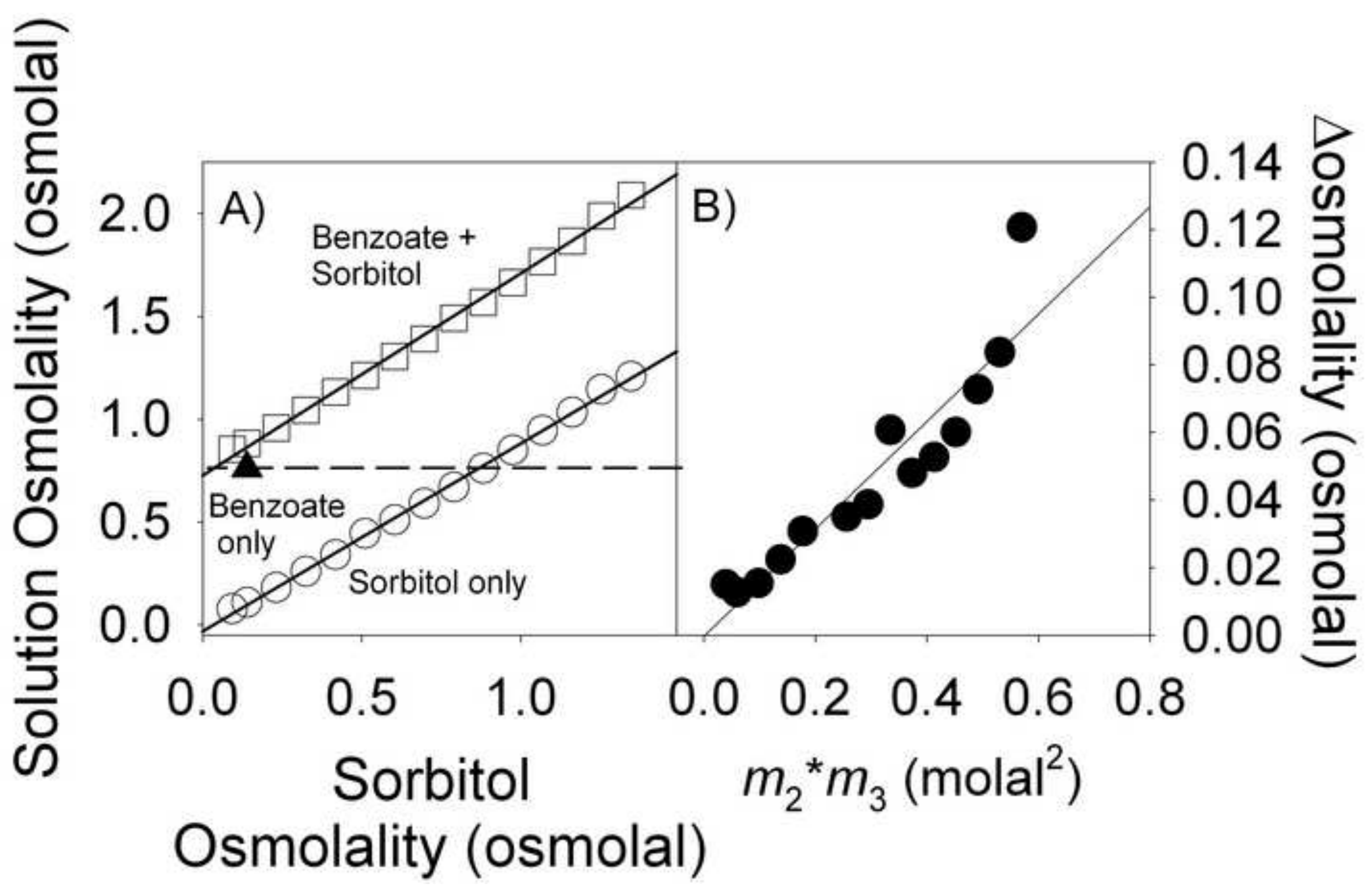




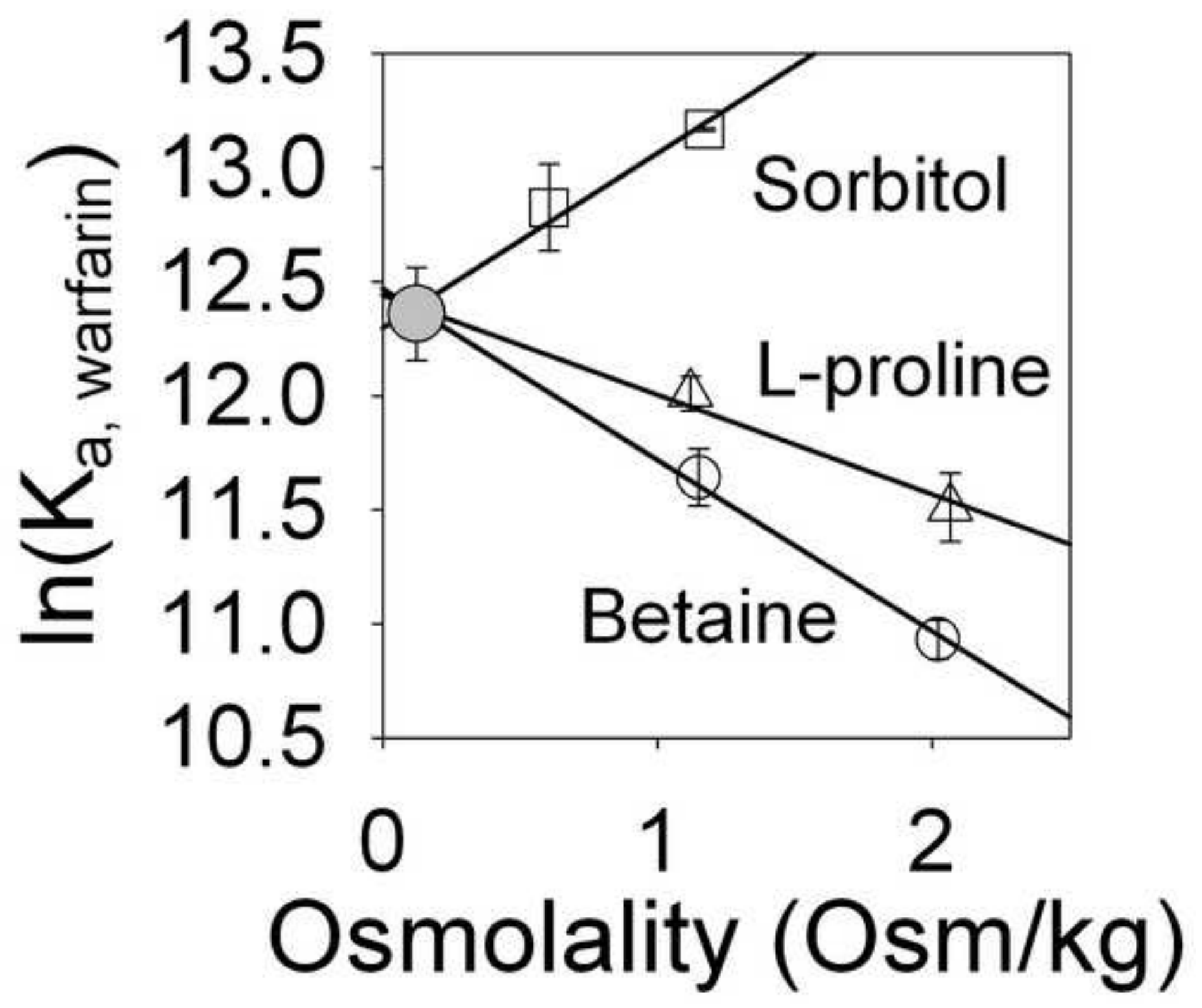

